\title{
A new phenomenon in interference effect on catamaran dynamic response
}

\author{
Amir Honaryar a, Mahmoud Ghiasi ${ }^{\text {a,* }}$, Pengfei Liu ${ }^{\text {b,c }}$, Arash Honaryar a \\ ${ }^{a}$ Department of Maritime Engineering, Amirkabir University of Technology, Hafez Avenue, 15875-4413 Tehran, Iran \\ ${ }^{b}$ Marine, Offshore, and Subsea Technology, School of Engineering, Newcastle University, Newcastle upon Tyne, NE1 7RU, \\ United Kingdom \\ ${ }^{c}$ International School of Marine Science and Engineering, Harbin Institute of Technology, Weihai, Shandong, 264209,
}

China

\begin{abstract}
Interference effect between catamaran demi-hulls has been considered as an adverse fluid-solid interaction; the narrower separation distance between the two hulls, the greater drag force acts upon the catamaran. However, this study is aimed at introducing a novel phenomenon contrasting outcome in semi-planing and planing regimes. As speed and accordingly the Froude number increase the catamaran transits across different modes, free surface profile becomes complicated and so does the interference effect as well as the prediction of catamaran dynamic response. The situation will be even more complex if demi-hull separation narrows where nonlinearity in interference effect is more pronounced. So, free-running tests in six degrees of freedom as well as obtaining fluid flow characteristics using computational fluid dynamics were conducted for a high-speed catamaran vehicle with asymmetric non-prismatic demi-hulls to tackle the problem. The results of catamaran dynamic response reveal that not only is drag reduced substantially up to $15 \%$, but also trim angle diminishes by $30 \%$ as hulls separation distance decreases in semi-planing and planing modes. In other words, with increasing speed, and decreasing trim angle by $2.3^{\circ}$, the current method achieved the goal of consequently reducing the risk of porpoising instability, without the increase of delivered power.
\end{abstract}

Keywords: Catamaran dynamic response, Interference effect, Hull separation, Drag, Trim, Porpoising

\footnotetext{
* Corresponding author: Mahmoud Ghiasi E-mail: mghiasi@aut.ac.ir
} 


\begin{tabular}{|c|c|c|c|}
\hline Nomenclature & & $s$ & demi-hulls separation \\
\hline$a_{1}$ & coefficient for $k$ and $\omega$ & $s_{\max }$ & maximum separation \\
\hline$\{B\}$ & body-fixed Cartesian coordinate system & $s_{\min }$ & minimum separation \\
\hline$b$ & demi-hull breadth & $s / L$ & separation ratio \\
\hline $\mathrm{c}$ & Node number & $T$ & draft \\
\hline$C_{A}(v)$ & hydrodynamic Coriolis, centripetal matrix & $T_{a}$ & aft draft of vehicle \\
\hline$C_{B}$ & center of buoyancy & $t$ & Time \\
\hline$C F L$ & Courant-Frederich-Lewis number & $U$ & vehicle advance velocity \\
\hline$C_{G}$ & center of gravity & $u, v, w$ & vehicle linear velocity components \\
\hline$C_{R B}(v)$ & rigid body Coriolis, centripetal matrix & $\bar{V}$ & time-averaged fluid velocity vector \\
\hline$C_{U}$ & speed coefficient & $v$ & vehicle velocity vector \\
\hline$D(v)$ & hydrodynamic damping matrix & $\overline{V^{\prime}}$ & time-averaged velocity fluctuating vector \\
\hline$d_{p}$ & propeller diameter & $X$ & drag force (resistance) \\
\hline$E$ & error & $x, y, z, \phi, \theta, \psi$ & vehicle position components in $\{I\}$ \\
\hline$\overline{f_{b}}$ & source term & $y^{+}$ & non-dimensional distance of first layer \\
\hline Fr & Froude number & $Z$ & lift force \\
\hline$F_{2}$ & blending function & $\alpha$ & volume fraction \\
\hline$g$ & gravitational acceleration & $\beta$ & deadrise angle \\
\hline$G(\eta)$ & restoring matrix & $\varepsilon$ & shaft angle \\
\hline$H$ & demi-hull height & $\phi$ & variable at integration points \\
\hline$\{I\}$ & inertial Cartesian coordinate system & $\phi_{c}$ & value of $\phi$ at node $c$ \\
\hline$I_{p}$ & pitch moment of inertia around $C_{G}$ & $\phi_{i p}$ & value of $\phi$ at integration point \\
\hline$i p$ & integration point & $\phi_{u p}$ & value of $\phi$ at upwind node \\
\hline$J(\eta)$ & transformation matrix & $\eta$ & vehicle position vector \\
\hline$k$ & turbulence kinetic energy & $\eta_{D}$ & delivered efficiency \\
\hline$L$ & demi-hull length & $\kappa$ & factor in high resolution scheme \\
\hline$l$ & length below water surface & $\mu$ & molecular or dynamic viscosity \\
\hline$L_{C B}$ & longitudinal center of buoyancy & $\mu_{a}$ & dynamic viscosity of air \\
\hline$L_{C G}$ & longitudinal center of gravity & $\mu_{e f f}$ & effective viscosity \\
\hline$m$ & vehicle mass & $\mu_{e f f, k}$ & effective turbulent viscosity for $k$ \\
\hline$\dot{m}_{i p}$ & mass flux & $\mu_{e f f, \omega}$ & effective turbulent viscosity for $\omega$ \\
\hline$M_{A}$ & added mass and inertia matrix & $\mu_{t}$ & eddy or turbulent viscosity \\
\hline$M_{R B}$ & rigid body inertia matrix & $\mu_{w}$ & dynamic viscosity of water \\
\hline$N$ & Node & $v_{t}$ & turbulent kinematic viscosity \\
\hline$N_{c}$ & shape function for node $c$ & $\rho$ & fluid density \\
\hline$n$ & propeller revolution & $\rho_{a}$ & density of air \\
\hline $\bar{P}$ & time-averaged fluid pressure & $-\rho \overline{V^{\prime} V^{\prime}}$ & Reynolds stress tensor \\
\hline$P_{D}$ & delivered power & $\rho_{w}$ & density of water \\
\hline$P_{d}$ & dynamic pressure & $\tau$ & forces and moments vector \\
\hline$P_{\text {hyd }}$ & hydrostatic pressure & $\tau_{E}$ & environmental forces and moments vector \\
\hline$P_{s}$ & static pressure & $\theta$ & trim angle \\
\hline$P_{\text {stag }}$ & stagnation pressure $\left(P_{s}+P_{d}\right)$ & $\omega$ & specific dissipation rate \\
\hline$P_{\text {total }}$ & total pressure $\left(P_{\text {hyd }}+P_{s}+P_{d}\right)$ & $\overline{\mathfrak{I}}$ & time-averaged fluid stress tensor \\
\hline$p, q, r$ & vehicle angular velocity components & $\Delta t$ & time step \\
\hline$Q^{k}$ & source term for $k$ & $\Delta x$ & mesh cell dimension \\
\hline$Q^{\omega}$ & source term for $\omega$ & $\Delta y$ & first layer thickness \\
\hline $\boldsymbol{R}$ & vector from the upwind node to $i p$ & $\Delta \mathbb{N}_{j}$ & discrete outward surface vector \\
\hline $\begin{array}{l}\operatorname{Re}_{L} \\
S\end{array}$ & $\begin{array}{l}\text { Reynolds number } \\
\text { invariant measure of the strain rate }\end{array}$ & $\forall$ & control volume \\
\hline
\end{tabular}




\section{Introduction}

Water-hull interaction has always been responsible for either constructive or destructive phenomena involved in dynamic response of marine vehicles; particularly interacting more severely where the medium is surrounded by adjacent hulls [1]. The interconnection between ship vertical excitation and resonant piston-like sloshing in a moonpool is an example of unfavorable phenomenon analytically solved by Faltinsen, Rognebakke and Timokha

[2]. The moonpool breadth considerably affects fluid resonance such that narrower gap results in a higher resonant frequency and amplitude [3]. It may also lead to a motion-trapped mode for any side-by-side floating structures in free response to incident wave if they are placed at a specific distance apart [4], in which the separation distance variation changes structure natural frequency, and higher hydrodynamic forces imposed by liquid confined in between are resulting from shorter distance $[5,6]$ even in the case of submerged bodies near the free surface $[7,8]$. Playing a pivotal role in the performance of multiple bodies, clearance should be chosen in a way to restrict hydrodynamic force to the minimum. However, there is also the possibility of employing small-scale structures of suitable clearance or spacing to limit hydrodynamic force acting on large-scale structures such as using incline collar rings on bridge piers [9].

On the other hand, close proximity can cause an advantageous phenomenon especially in terms of propulsion and energy harvesting. Liu [10] enhanced and used a three-dimensional time-domain panel method code, DF_OSFBEM, to demonstrate how thrust and efficiency of a twin-foil propulsor benefiting from the so-called Wing-In-Ground (WIG) effect, in comparison with a single foil one, are enhanced by $50 \%$ and $20 \%$, respectively. Moreover, decreasing distance between foils enhanced both thrust and efficiency [10-12]. Furthermore, by diminishing flow separation, extra thrust and efficiency will be generated if the foils in biplane arrangement are equipped with an auto-pitch mechanism along with an elastic pitching axis $[13,14]$. Liu [15] further enhanced and used an unsteady panel method code, named PROPELLA, and devised a novel dual-foil marine current turbine in order to produce more energy using WIG effect [16].

However, because the ratio between resistance components of catamaran vessels substantially alters in different range of Froude numbers (Fr), it is a formidable challenge to decide whether interference effect due to demi-hull separation is constructive or not. At a low speed $(\mathrm{Fr}<0.3)$, water friction resistance overcomes wavemaking element, whereas in the range of $0.3<$ Fr $<0.75$ the total resistance will be dominated by wave-making component, gradually by reaching the high-speed mode $(\mathrm{Fr}>0.75)$ their portions will be equalized at $\mathrm{Fr}=0.75$. Eventually, as speed grows friction element (or viscous resistance) exceeds wave-making resistance once more where a planing configuration with a V bottom rather than a round bilge (or U bottom) is highly recommended to 
minimize friction drag utilizing dynamic lift of water [17]. Notwithstanding that demi-hull separation does not have noticeable influence on the total resistance and correspondingly the friction resistance in the first range (Fr $<0.3$ ), it significantly affects the total resistance when $0.3<\mathrm{Fr}<0.75$ in such a way that the narrower gap imposes more drag force on the vessel clarifying the interaction effect is deeply rooted in the wave-making interference in the latter [18-28].

Evaluating catamaran in two Degrees of Freedom (DOF), free to pitch and heave, Zaghi, Broglia and Di Mascio [25] perceived the presence of two humps in the resistance-velocity profile at approximately Froude numbers of 0.3 and 0.5 . The second peak, to which being in close relationship with increasing trim and sinkage was referred, was found to be strongly dependent on separation length as well. Soon thereafter, Broglia, Jacob, Zaghi, Stern and Olivieri [27] discerned how these two humps, specifically the second one in which resistance and trim surge up to $30 \%$ and $100 \%$ (from $1^{\circ}$ to $2^{\circ}$ ) at the narrowest separation respectively, relate to the presence and position of wave crest and trough resulting from superposition of waves radiated from demi-hulls in the separation area. In the case of shallow water, sea bottom effect will add to the resistance, trim and sinkage likewise $[19,21,29,30]$. Taking advantage of the linearized wave theory, Millward [31] figured out the effect of restricted water depth on resistance of isolated hull is approximately similar to that of the catamaran, regardless of separation ratio. But, Castiglione, He, Stern and Bova [32] pointed out the interference effects are more vigorous in shallow water than in deep water so that its maximum impact appear sooner at $0.3<\mathrm{Fr}<0.4$ where trim and sinkage significantly vary in magnitude. The Froude number of 0.4 was also introduced as the situation in which lowering the lateral spacing notably enlarges the drag force [33]. Similarly in the case of encountering sea waves, the reduction in hull lateral separation intensifies dynamic trim and sinkage [34]. Or even when there is a relative motion between two neighboring bodies, the slower one experiences stronger hydrodynamic loads as well as greater trim and sinkage due to the interaction [35]. In order to better capture the variations of trim and sinkage due to interference effect, Li, Gong, Ma and Yan [36] developed a fully nonlinear model of free surface based on boundary element method. Their findings showed that the smaller the separation ratio is, the more pronounced is the nonlinearity of the free surface.

Furthermore, Souto-Iglesias, Fernández-Gutiérrez and Pérez-Rojas [26] demonstrated that there is a remarkable deviation in the results of free and fixed models. The resistance in the free condition is by far greater than that of the captive model (without any degrees of freedom) as is the case in the research provided by Chen, Zhu, Song and Fan [37] indicating the strong interaction between catamaran dynamic response and fluid forces. In the same way Insel and Molland [38]'s investigations into high-speed displacement catamarans reflected 
substantial differences between trim and sinkage of the catamaran and those of the monohull. After interestingly breaking down the total resistance into wave making and viscous components, they found unlike the former, the viscous resistance is independent of hull separation at moderate Froude numbers. Afterwards Sahoo, Salas and Schwetz [39] practically proposed a regression formula for catamaran resistance considering the separation ratio following both experimental available data and numerical techniques.

On the contrary, in the third phase $(\mathrm{Fr}>0.75)$ the viscous resistance is just as significant as the wave making component and gradually overwhelms the latter so that the interference effect analysis becomes more complicated and extremely dependent on the catamaran running attitude. Although it is not simple to distinguish between semiplaning and planing modes, typically it is considered semi-planing if $0.4-0.5<\mathrm{Fr}<1.0-1.2$ and planing if $\mathrm{Fr}>$ 1.0-1.2 [40] so either one may occur for Fr $>0.75$. In the planing regime, Savitsky and Dingee [41] outlined how closely demi-hulls in a catamaran vessel and wings in a flight side by side resemble each other. As a result of putting two wings adjacent to each other as well as the interference of their trailing vortices, an upwash velocity will be induced gives rise to more lift efficiency for each wing than the case they are infinitely far apart. Additionally, the lift will increase further if the lateral spacing decreases. However, they declared for the reason that the catamaran is a low aspect ratio lifting surface advancing through the air/water interface whose profile is deformed by the interference effect, this phenomenon cannot be analytically solved analogous with wings in aerodynamics. Savitsky and Dingee [41] experimentally found that due to the proximity effect the lift can increase up to $47 \%$ (the maximum was observed in correspondence of the zero beam spacing). Afterwards, Liu and Wang [42] adapted Savitsky [43]'s formula for the lift of V-shaped catamarans by introducing an interference factor ranging from 1.0 to $2.0^{1 / 2}$ and then Lee [44] proposed an improved interference factor as a function of both separation ration and speed coefficient. Experiments carried out by Sherman, Fisher and Couch [45] on a planing catamaran hull divulged reduction in resistance for the least hull spacing in some range of Froude numbers, even though specific reason for that or any investigation on dynamic response of the hull (trim and heave) was not reported.

With a focus on the interference effect in planing catamaran, Wu [46] analyzed the water entry problem of twin wedges and spotlighted the pressure distribution deep dependency on the interaction of the wedge nearby, and particularly a sharp increase in pressure when twin wedges and free surface are in close proximity. To deal with the nonlinearity in the water entry problem, Faltinsen and Semenov [47] presented a nonlinear analytical solution for resolution of the analytical function as the complex potential of a free surface flow. In addition, to detect the 3D effect of dynamic pressure due to hydrodynamic load Jalalisendi and Porfiri [48] and Xie, Liu, Yu 
and Ren [49] resolved the water entry problem using rigorous experiments. Mayer and Krechetnikov [50] and Wang and Duncan [51] detected the viscosity and surface tension effects on the flow field through experiments as well. Some other numerical research into the water entry discovered a conspicuous rise in the maximum pressure coefficient and impact force acting on the catamaran because of reduction in demi-hulls separation $[52,53]$. With regard to the impact force, nonetheless, Shabani, Lavroff, Holloway, Davis and Thomas [54] studied the effect of wet-deck geometry on the slamming load and concluded that lower tunnel clearance induces higher slamming load and vertical bending moment that would be detrimental from structural perspective $[55,56]$.

Although two-dimensional analysis of water entry problem has provided precious information for planing catamarans, investigation in three dimensions presents new insight into and reveals more realistic findings of interference effects. Yengejeh, Amiri, Mehdigholi, Seif and Yaakob [57] applied three dimensional Computational Fluid Dynamics (CFD) to solve Reynolds-Averaged Navier Stokes (RANS) equations in order to determine the flow field around a prismatic asymmetric planing catamaran. They examined interference effect on viscous, pressure, air, and water resistance separately and found that at very high speeds the viscous and air components are as important as the pressure and water resistance, besides both the lift force and the wetted surface, also known as the pressure area [43], increased by decreasing demi-hulls separation. However, they did not consider the variation of trim and rise (dynamic response of the vessel) due to fluid-solid interaction in different separations that may affect all resistance components especially the viscous term. Mousaviraad, Wang and Stern [58] coupled RANS equations to rigid body motions of a planing monohull using CFDShip-Iowa solver to evaluate resistance, trim, rise and existence of porpoising instability in free condition. It was stated that despite rise of the hull that tended to increase, the trim was reduced as Fr increased. Considering the flow between demihulls planing parallel to each other as a potential flow, Bari and Matveev [59] reached the similar output that lift coefficient was risen for smaller hull spacing at moderate and high Froude numbers whereas fallen at low Froude numbers [60]. Nevertheless, Kramer, Maki and Young [61] ascertained that because of nonlinear and viscous effects, potential-flow assumptions cannot fully assimilate the planing problem at Froude numbers lower than 0.8 in comparison with a nonlinear CFD solver. Conversely these two approaches are in good agreement at higher Fr. It should be also noted that longitudinal wave-interference effects play a prominent part at $\mathrm{Fr}<0.9$ while lateral wave-interference effects are dominant at Fr > 1.0 where a wake mostly constituted of divergent waves exists whose angle is a kinematic feature, almost regardless of hull shape, dependent on 1/Fr [62-64].

Since the flow pattern around each catamaran demi-hull is asymmetrical, a cross flow inducing hydrodynamic forces occurs. Wan and Yeung [65] addressed the cross-flow induced interference effect in a potential flow model 
and found out that in opposition to the wave resistance dominating at medium Fr, the drag induced by cross flow is dominant at high Fr. This cross flow may generate a wake with robust vortex shedding whose strength and configuration strongly correlate with the gap between two neighboring bodies that was studied by Dadmarzi, Narasimhamurthy, Andersson and Pettersen [66] using direct numerical simulation. Also longitudinal bilge vortex originating from the cross flow significantly affects the interference phenomena at high Fr and therefore CFD analysis would offer a comprehensive interference study of the flow field details around the catamaran [25]. And besides, the cross flow may also cause the flow separation phenomenon along the keel leading to vortices generation that CFD is capable of capturing [67]. In addition, Miao, Zhao and Wan [68] found that by making the lateral spacing shorter especially at $\mathrm{Fr}=0.4$ and 0.45 , flow between demi-hulls become more disturbed, and as a result, the cross flow strengthens resulting in increasing resistance. They nonetheless did not examine the effect of separation ratio on the cross flow at high Froude numbers $(\mathrm{Fr}>0.75)$, as their investigation was limited up to Fr $=0.55$. Regarding nonlinear dynamic response of the vessel, Li, Zhang, Zhang and Li [69] and Dash, Nagarajan and Sha [70] predicted coupled motions in two (pitch-roll) and four (surge-sway-yaw-roll) degrees of freedom using simulations based on bifurcation analysis, respectively.

However, simulations and CFD analysis may not supersede experimentation and vice versa, in fact, experiment can play a supplementary role for simulations. Carrying out model tests for a wide range of Froude numbers, $0.1<$ Fr $<1.1$, Yang, Lin, Li, Guo, Sun and Yang [71] measured dynamic response consisting of trim and rise of a catamaran in addition to drag. Analyzing dynamic response facilitates detailed examination of specific aspects such as hydrodynamic stability other than solely surveying resistance. Because it is of great importance to design a marine vehicle based on both points of view [72]. In so doing Honaryar, Mousavizadegan and Ghassemi [73] and Pandey and Hasegawa [74] employed a combined experimental and numerical method to evaluate the turning circle maneuver of a catamaran. Also, in order to achieve an optimal configuration considering interference effect and to compute wave resistance, Yu, Lecointre and Yeung [75] combined experimental longitudinal wave-cut measurements and analytical expressions. Thornhill, Veitch and Bose [76] applied self-propulsion tests to assess dynamic response of a monohull planing vessel and its porpoising to variation in Froude number and longitudinal center of gravity, respectively, and afterwards Rakesh, Rao and Subramanian [77] combined CFD based on RANS scheme with free running tests to evaluate running trim and dynamic emergence.

According to the previous studies, so far it has been concluded that the interference effect is a disadvantageous phenomenon at medium Froude numbers $(0.3<\mathrm{Fr}<0.75)$ indicating that a larger drag is imposed on the catamaran 
than twice that of the monohull. However, far too little research has focused on whether the interference effect is destructive or constructive at high Froude numbers $(\mathrm{Fr}>0.75)$ considering the dynamic response of the catamaran vehicle due to the fluid-solid interaction in computing the drag. The present study is aiming for a comprehensive research on the interference phenomena at both medium and high Froude numbers considering the catamaran dynamic response, and hopefully offering a novel phenomenon at high Froude numbers. The novel phenomenon presented in this study is called 'Honaryar' consists of two Persian words meaning 'The Art of the Partner' referring to the fact that the interference effect due to the partnership of adjacent demi-hulls is constructive at high Froude numbers. Free-running tests in Six Degrees of Freedom (6DoF) have been carried out for a high-speed catamaran vehicle with asymmetric non-prismatic demi-hulls named Zayandeh Rud Autonomous Surface Vehicle (ZRASV) [78] after Zayandeh Rud River. Furthermore, in order to survey the flow field around the demi-hulls in detail, a CFD analysis has been conducted.

\section{ZRASV specifications}

Zayandeh Rud Autonomous Surface Vehicle (ZRASV) is a catamaran of which main dimensions and specifications along with the inertial Earth-fixed $\{I\}$ and the moving body-fixed $\{B\}$ right-handed Cartesian coordinate systems are illustrated and tabulated in Fig. 1 and Table 1, respectively. The position vector $\eta=[x, y, z, \phi, \theta, \psi]^{T}$ is defined in the inertia frame while the velocity vector $v=[u, v, w, p, q, r]^{T}$ is defined in the body-fixed frame. ZRASV is a high-speed self-propelled vehicle driven by an electric motor providing advance speed $U$ up to about $6 \mathrm{~m} / \mathrm{s}$ equivalent to the Froude number $F r=U /(g L)^{0.5}$ of 1.75 based on the demi-hull length $L=1.200 \mathrm{~m}$, and a speed coefficient $C_{U}=U /(\mathrm{gb})^{0.5}$ of 4.82 based on the demi-hull breadth $b=0.158 \mathrm{~m}(\mathrm{~g}$ is designated for the gravitational acceleration).

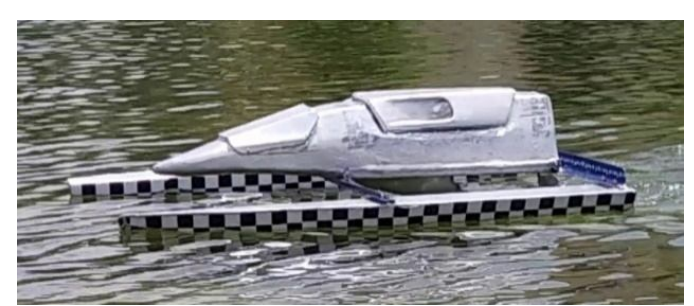

(a)

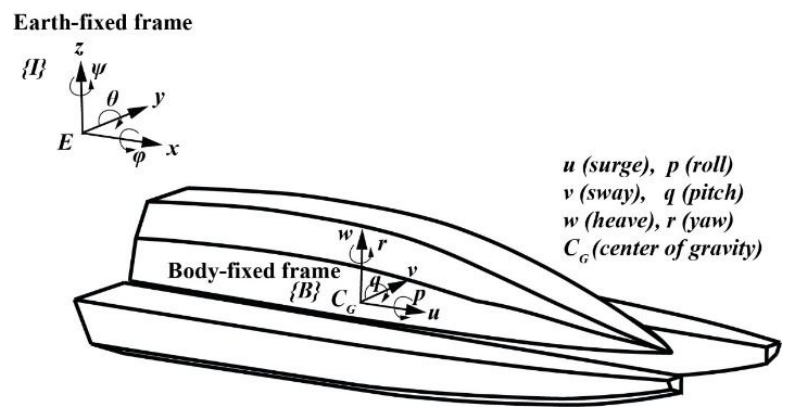

(b) 


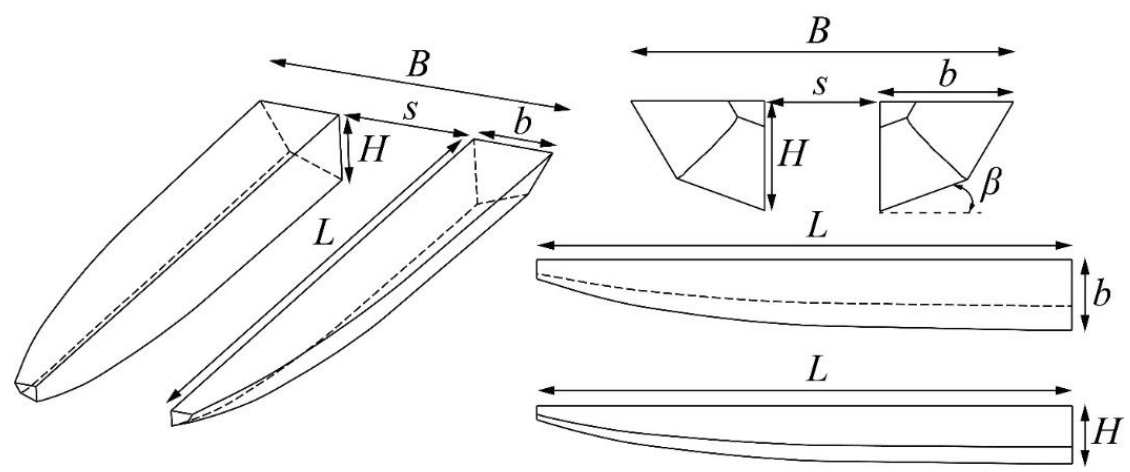

(c)

Fig. 1. The high-speed self-propelled catamaran, ZRASV (a), inertial Earth-fixed $\{\boldsymbol{I}\}$ and moving body-fixed $\{\boldsymbol{B}\}$ coordinate systems (b), and its asymmetric non-prismatic demi-hulls geometry and main dimensions (values are given in Table 1) (c)

Table 1. ZRASV main features and dimensions

\begin{tabular}{|c|c|c|c|c|c|c|c|c|}
\hline $\begin{array}{l}\text { Main } \\
\text { features }\end{array}$ & Length & Beam & $\begin{array}{l}\text { Demi-hulls } \\
\text { separation }\end{array}$ & $\begin{array}{l}\text { Demi-hull } \\
\text { beam }\end{array}$ & $\begin{array}{l}\text { Demi-hull } \\
\text { height }\end{array}$ & Mass & \multicolumn{2}{|c|}{$\begin{array}{l}\text { Pitch moment of } \\
\text { inertia around } C_{G}\end{array}$} \\
\hline Symbol & $L(\mathrm{~m})$ & $B(\mathrm{~m})$ & $s(\mathrm{~m})$ & $b(\mathrm{~m})$ & $H(\mathrm{~m})$ & $m(\mathrm{~kg})$ & \multicolumn{2}{|c|}{$I_{p}\left(\mathrm{~kg} \cdot \mathrm{m}^{2}\right)$} \\
\hline Value & 1.20 & $0.45-1.05$ & $0.13-0.73$ & 0.158 & 0.130 & 13.180 & \multicolumn{2}{|c|}{1.290} \\
\hline Main & \multicolumn{2}{|c|}{ Longitudinal Center of } & \multicolumn{2}{|c|}{ Longitudinal Center of } & Propeller & Advance & Shaft & Deadrise \\
\hline features & \multicolumn{2}{|c|}{ Gravity $\left(C_{G}\right)$} & \multicolumn{2}{|c|}{ Buoyancy $\left(C_{B}\right)$} & revolution & velocity & angle & angle \\
\hline Symbol & \multicolumn{2}{|c|}{$L_{C G}(\mathrm{~m})$} & \multicolumn{2}{|c|}{$L_{C B}(\mathrm{~m})$} & $n$ (rpm) & $U(\mathrm{~m} / \mathrm{s})$ & $\varepsilon\left(^{\circ}\right)$ & $\beta\left(^{\circ}\right)$ \\
\hline Value & \multicolumn{2}{|c|}{0.438 (from stern) } & \multicolumn{2}{|c|}{0.477 (from stern) } & $0-4787$ & $0-5.88$ & 10 & 20 \\
\hline
\end{tabular}

The vehicle is thrust by a two-blade propeller of $0.065 \mathrm{~m}$ diameter of which thrust line is inclined at angle of 10 degrees contributing to lift force apart from thrust force. The propeller revolution is adjusted by an electronic motor drive by which the electric motor speed is controlled as well. As depicted in Table 1, the center of gravity is located slightly behind the center of buoyancy and therefore when floating on the water at rest, the vehicle is trimmed by aft as great as $3.7^{\circ}$ also called static trim to have both centers vertically aligned because of equilibrium.

\section{Numerical analysis}

\subsection{Governing equations}


Under the assumption of rigidity of the body, the catamaran kinematics and kinetics satisfying equations of motion are defined. External forces imposing on the body are computed from fluid flow motion equations through RANS scheme in CFD. As it was shown in Fig. 1b and in accordance with Fossen [79] kinematic and kinetic equations of the vehicle can be stated based on the inertial Earth-fixed $\{I\}$ and the moving body-fixed $\{B\}$ righthanded Cartesian coordinate systems, respectively, as follows:

$$
\dot{\eta}=J(\eta) v
$$

$$
\left(M_{R B}+M_{A}\right) \dot{v}+\left[\left(C_{R B}(v)+C_{A}(v)\right)\right] v+D(v) v+G(\eta)=\tau_{E}+\tau
$$

where the position vector in the Earth-fixed frame $\eta=[x, y, z, \phi, \theta, \psi]^{T}$ and the velocity vector in the body-fixed frame $v=[u, v, w, p, q, r]^{T}$ are linked to each other through the transformation matrix $\boldsymbol{J}(\boldsymbol{\eta})$. Hydrodynamic coefficient matrices $M_{R B}, M_{A}, C_{R B}(v), C_{A}(v), D(v)$, and $G(\eta)$ represent the rigid body inertia, added mass and inertia, rigid body Coriolis and centripetal, hydrodynamic Coriolis and centripetal, damping, and restoring matrix, respectively. The $\tau_{E}$ denotes environmental forces and moments vector and $\tau$ signifies propeller and rudder forces and moments vector. It is supposed that the water is calm, thereby $\tau_{E}=0$ means neither wind nor environmental wave exists. Coriolis and centripetal terms in Eq. (2) can be disregarded because the problem does not involve large scale motion in the ocean and the catamaran merely moves forward in a straight line devoid of turning. Time averaged continuity and momentum equations for incompressible, viscous flow using RANS approach are respectively written as [80]

$$
\begin{aligned}
& \nabla \cdot[\rho \overline{\boldsymbol{V}}]=0 \\
& \frac{\partial}{\partial t}[\rho \overline{\boldsymbol{V}}]+\nabla \cdot\{\rho \overline{\boldsymbol{V} \boldsymbol{V}}\}=-\nabla \overline{\boldsymbol{P}}+\left[\nabla \cdot\left(\overline{\mathfrak{I}}-\rho \overline{\boldsymbol{V}^{\prime} \boldsymbol{V}^{\prime}}\right)\right]+\overline{\boldsymbol{f}}_{b}
\end{aligned}
$$

where $\rho$ represents the fluid density, $t$ stands for time and $\overline{\boldsymbol{V}}, \overline{\boldsymbol{V}}^{\prime}, \bar{P}, \overline{\mathfrak{I}}$, and $\overline{\boldsymbol{f}_{b}}$ designate the time-averaged fluid velocity vector, fluid velocity fluctuating components, fluid pressure, fluid stress tensor and the source term in the momentum equation, respectively. However, due to the non-linear expression $-\rho \overline{\boldsymbol{V}^{\prime} \boldsymbol{V}^{\prime}}$ so called Reynolds stress tensor whose components left as six unknowns, six more equations are needed.

\subsection{Numerical strategy}

As a proper strategy for dealing with the Reynolds stress tensor components, a two-equation turbulence model known as the Shear Stress Transport (SST) $k-\omega$ is implemented to close the set of RANS equations. Where $k$ 
signifies the turbulence kinetic energy and $\omega$ is the specific dissipation rate symbolizes the rate of converting turbulence kinetic energy into the internal thermal energy. In this model, two sets of additional transport equations each of which includes three components in Cartesian coordinate system for $k$ and $\omega$ are expressed as [80]

$$
\begin{aligned}
& \frac{\partial}{\partial t}(\rho k)+\nabla \cdot[\rho \overline{\boldsymbol{V}} k]=\nabla \cdot\left[\mu_{e f f, k} \nabla k\right]+Q^{k} \\
& \frac{\partial}{\partial t}(\rho \omega)+\nabla \cdot[\rho \overline{\boldsymbol{V}} \omega]=\nabla \cdot\left[\mu_{e f f, \omega} \nabla \omega\right]+Q^{\omega}
\end{aligned}
$$

where $\mu_{e f f, k}, \mu_{e f f, \omega}, Q^{k}$, and $Q^{\omega}$ denote effective turbulent viscosities and source terms for $k$ and $\omega$, respectively.

To conserve the fluid flow mass and momentum, an element-based finite volume method is applied in the RANS solver, ANSYS CFX [81] in which data including fluid properties and solution variables are saved at the nodes. This method of discretization is also called the vertex-centered or the dual median method. In the present study, two types of elements are used to discretize the spatial domain: 1- Hexahedral element used as a Structured Mesh (SM) made of 8 nodes, and 2- Wedge element used as an Unstructured Mesh (UM) made of 6 nodes. Fig. 2 illustrates a control volume among four hexahedral elements, for instance, in two-dimensional view where only four nodes of each element are shown for simplicity. After integrating the fluid flow equations over each control volume, volume integrals and surface integrals are discretized inside each element sector and at the integration points (ip) at which the solution fields are approximated using finite-element shape functions, respectively, and subsequently accumulated or distributed to the corresponding control volume.

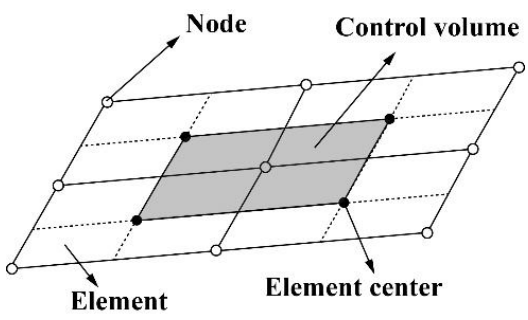

(a)

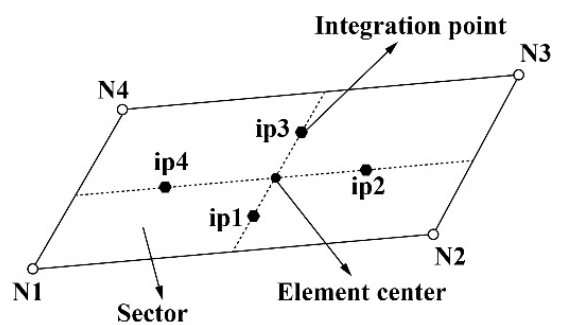

(b)

Fig. 2. The control volume among four hexahedral elements in two-dimensional view (a), and a hexahedral element with the locations of integration points $i p$ with respect to nodes $N$, only 4 nodes out of 8 are shown (b)

Discretized form of Eq. (3) and (4) in Cartesian coordinate system using index notation can be defined as [81]: 


$$
\begin{aligned}
& \forall\left(\left(\rho-\rho^{0}\right) / \Delta t\right)+\sum_{i p} \dot{m}_{i p}=0 \\
& \forall\left(\left(\rho \bar{V}_{i}-\rho^{0} \bar{V}_{i}^{0}\right) / \Delta t\right)+\sum_{i p} \dot{m}_{i p}\left(\bar{V}_{i}\right)_{i p}=\sum_{i p}\left(\bar{P} \Delta \mathbb{N}_{i}\right)_{i p}+\sum_{i p}\left(\mu_{e f f}\left(\partial \bar{V}_{i} / \partial x_{j}+\partial \bar{V}_{j} / \partial x_{i}\right) \Delta \mathbb{N}_{j}\right)_{i p}+\bar{f}_{b_{i}} \forall
\end{aligned}
$$

where the mass flux is defined as $\dot{m}_{i p}=\left(\rho \bar{V}_{j} \Delta \mathbb{N}_{j}\right)_{i p}$, the symbols $\forall, \Delta t$ and $\Delta \mathbb{N}_{j}$ signify the control volume, the time step, and the discrete outward surface vector, respectively. The subscript ip and the superscript ${ }^{0}$ stand for the integration point and the old time level, respectively. The effective viscosity $\mu_{\text {eff }}$ is the sum of two terms: the molecular or dynamic viscosity $\mu$ and the eddy or turbulent viscosity $\mu_{t}$. In SST $k-\omega$ turbulence model, the turbulent viscosity is defined as $\mu_{t}=\rho v_{t}=\rho\left(a_{1} k / \max \left(a_{1} \omega, S F_{2}\right)\right)$ in which $v_{t}$ represents the turbulent kinematic viscosity, $S$ refers to an invariant measure of the strain rate and $F_{2}$ indicates a blending function. Both $k$ and $\omega$ multiplied by the coefficient $a_{1}$ are computed by discretizing integral equations of Eq. (5) and (6).

The approximation of values of a variable $\phi$ at integration points required in the advection term are performed by means of a high resolution scheme so that $\phi_{i p}=\phi_{u p}+\kappa \nabla \phi . \Delta \boldsymbol{R}$ where the second term in the right hand-side is called the numerical advection correction comprising the factor $\kappa$ and the vector $\boldsymbol{R}$ from the upwind node to the integration point. A special nonlinear strategy for $\kappa$ at each node is employed such that $\kappa$ does not exceed 1 but is near 1 as much as possible. Following assessing the advective flux using $\kappa$ and $\nabla \phi$ from the upwind, the value at integration point $\phi_{i p}$ is estimated from the value at upwind node $\phi_{u p}$. For advection terms included in transport equations in the turbulence model, a first order upwind difference scheme is chosen for discretization. In this scheme the factor $\kappa=0$ makes the approach more robust, however, creating some diffusive discretization errors tending to smear sharp spatial gradients are inevitable. Taking into consideration the spatial derivatives included in the diffusion terms, the standard finite-element approach is adopted in which in the $x$ direction, for instance, $\partial \phi /\left.\partial x\right|_{i p}=\sum_{c} \partial N_{c} /\left.\partial x\right|_{i p} \phi_{c}$ where $N_{c}$ is the shape function for node $c$. There are 8 and 6 shape functions for each hexahedral and wedge element, respectively.

Including two phases, water and air, the fluid flow equations cannot be solved unless the portion of each phase in the computational domain is determined specifically in the proximity of interface whose profile should be tracked. Even though analytical solutions provide precise answer for interface form of some straightforward problems such as a two-phase Couette flow [82], numerical solutions are acceptable alternatives to more complex flow structures. For tracing the free surface profile the Volume-of-Fluid (VOF) model is applied in which the fluid 
density $\rho$ and viscosity $\mu$, as a part of effective turbulent viscosity, are inserted into Eq. (3)-(6) through the definitions

$$
\begin{aligned}
& \rho=\rho_{w} \alpha+\rho_{a}(1-\alpha) \\
& \mu=\mu_{w} \alpha+\mu_{a}(1-\alpha)
\end{aligned}
$$

where symbols $\rho_{w}, \mu_{w}, \rho_{a}$, and $\mu_{a}$ in turn signify density and viscosity of water and air. The unknown $\alpha$ indicates the volume fraction of each phase in any computational cell and amounts to 1 and 0 for cells entirely filled with water and air, respectively, otherwise between 0 and 1 for the cells cut by the interface. Under kinematic condition of the free surface, the substantial derivative comprising local and convective rates of changes of $\alpha$ must equal zero from which $\alpha$ is obtained by solving

$$
\frac{D \alpha}{D t}=\frac{\partial \alpha}{\partial t}+\overline{\boldsymbol{V}} \cdot \nabla \alpha=0.0
$$

The Eq. (11) is also called the convection transport equation for the volume fraction distribution that should be addressed simultaneously with RANS equations because of the computational coupling between the volume fraction and the velocity field. In order to prevent the free surface from non-realistic deforming or being smeared as well as to deal with the numerical diffusion, an artificially stabilized compressive scheme [83] is used in the solver for the advection of volume fractions. This high resolution interface capturing approach benefits from the combination of the transient bounded version of QUICK and the upper bound of the convection bounded criteria [84]. Therefore there is neither an explicit interface reconstruction nor its difficulty to perform on unstructured meshes. This scheme applies the normalized face quantity for estimating a weighting factor of that quantity at a face as a function of the two cells sharing the face. In so doing, an implicit implementation on arbitrary meshes is made possible since all the data concerning the flow direction, the interface orientation and the free surface slope are collected by the weighting factors.

The preservation of boundedness with such an implicit implementation is, nevertheless, limited and sensitive to the Courant number, in the vicinity of the free surface in particular. To advect the volume fractions within the Courant-Frederich-Lewis (CFL) limitation, a very neat solution would be using the technique of sub-cycling by splitting the main loop time step into shorter steps. Generally, the CFL number is conditioned by $C F L=\bar{V} \Delta t / \Delta x \leq 1.0$ for numerical stability [85] where the time step $\Delta t$ correlates with the mesh cell dimension $\Delta x$ and flow speed $\bar{V}$. Also in the case of applying second-order approach for time integration it should be less than on half [86]. However, the time step estimation for satisfying the CFL condition primarily depends on the 
type of flow structure, solution variables, Froude number and complexity of the turbulence model. For example, providing practical guidelines, ITTC [87] recommended $\Delta t=0.005 \sim 0.01 L / U$ and $\Delta t=0.001 \sim 0.0025 L / U$ for standard pseudo-transient resistance computations in still water and Reynolds stress turbulence models, respectively. For low Froude numbers, a shorter time step may be required. Furthermore, for an intricate study of the biofouling impact upon ship resistance while using the SST $k-\omega$ turbulence model, Demirel, Turan and Incecik [88] suggested $\Delta t=0.0005 L / U$, one tenth of that recommended by ITTC [87]. Addressing the interference effect on resistance, as is the case in the present study, Elsherbiny, Terziev, Tezdogan, Incecik and Kotb [89] selected the time step based on $\Delta t=0.0035 \mathrm{~L} / U$ to meet the CFL condition for assessment the interference effect of canals with different cross sections on the ship hydrodynamic performance as it was also offered by Tezdogan, Incecik and Turan [86] to such interaction effects analyses resulting from a time step convergence study. Therefore, the last criterion was chosen for the current study as well.

Fig. 3 displays the computational model accompanied by mesh generated on the inside. For the sake of simplicity and reduction in computational time, the effect of superstructure, i.e. the middle body between two demi-hulls as depicted in Fig. 1, on interference effect is assumed to be negligible. Also due to the symmetry of catamaran about the $u w$-plane, only one demi-hull is considered in the computational domain. As illustrated in Fig. 3a the demi-hull is encompassed by a three-dimensional rectangular parallelepiped domain up to $4 L$ long, $2 L$ wide, and $2 L$ high in terms of the hull length $L$. As boundary conditions, the flow velocity is specified at the inlet surface, pressure at the outlet, symmetry at two sides, and opening at top boundary to let air flows freely across the boundary. The no slip condition for demi-hull wall, and lastly free slip wall (wall without shear force) at the bottom face were performed. The linear distribution of hydrostatic pressure in accordance with draft is assigned to the whole domain as an initial condition.
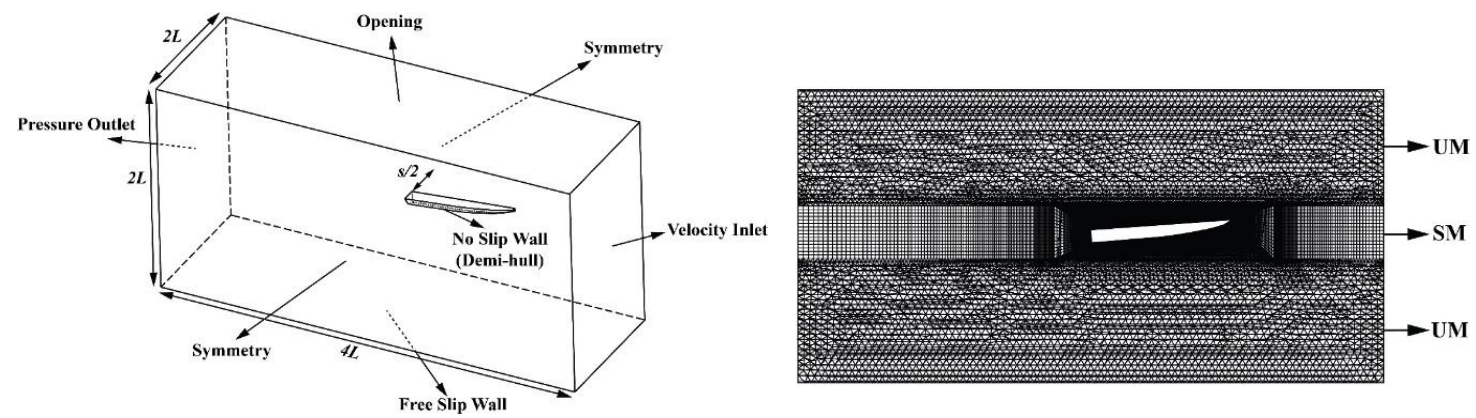

(b) 
(a)

Fig. 3. Computational domain and boundary conditions for CFD analysis (only one demi-hull has been considered for the sake of symmetry) (a), and grid generated in it (SM: Structured Mesh, UM: Unstructured

Mesh) (b)

Fig. 3b demonstrates how computational domain was discretized using a hybrid meshing scheme. The grid was generated near the demi-hull as well as the free surface region as structured mesh while unstructured mesh was dedicated to faraway areas to decrease the computational time. Structured mesh facilitates alignment with flow direction and minimizes numerical diffusion in areas with steep gradient flow characteristics such as near the wall or free surface. Furthermore, because the flow resolution in the solver is specified by the node number rather than element, far field unstructured mesh requires fewer memory than the structured one [90]. In addition to the importance of mesh independency of computational results, it is significant to determine non-dimensional distance of the first layer near the wall $y^{+}$in a suitable range. Although when choosing SST $k-\omega$ as a turbulence model it is advantageous to have $y^{+}<2$ for the low-Reynolds formulation, the results are still valid for range of $\mathrm{y}^{+}<300$ since the wall function approach governs, benefiting from coarser near-wall mesh and less computation

time. Using flat plate formulation $\Delta y=L y^{+} \sqrt{74} \operatorname{Re}_{L}^{-1 / 14}$ [81], where $\operatorname{Re}_{L}$ indicates the Reynolds number based on the length, the first layer thickness or the actual distance between the wall and first node $\Delta y$ was estimated and implemented in the mesh generation procedure.

\subsection{Validation against experimental data}

Drag force or resistance as an important integral variable and pressure as a prime local variable were validated against experimental data provided by Sottorf [91] for a flat plate to confirm the performance of the numerical model. Fig. 4a illustrates computed water volume fraction using CFD in the center plane (uw) for the flat plate planing at the advance velocity of $U=6 \mathrm{~m} / \mathrm{s}$, trim angle of $\theta=-6.53^{\circ}$, and length below water surface of $l=$ $0.250 \mathrm{~m}$ in which discrepancy $E$ of resistance $X$ compared with [91] is represented in Table 2.

Table 2. Validation for CFD prediction of flat plate resistance against experiment conducted by Sottorf [91]

\begin{tabular}{cccccc}
\hline & $U(\mathrm{~m} / \mathrm{s})$ & $\theta\left({ }^{\circ}\right)$ & $l(\mathrm{~m})$ & $X(\mathrm{~N})$ & $E(\%)$ \\
\hline CFD & 6.0 & 6.53 & 0.250 & 25.012 & 5.92
\end{tabular}




\begin{tabular}{lllll}
\hline Experiment & 6.0 & 6.53 & 0.250 & 26.585 \\
\hline
\end{tabular}

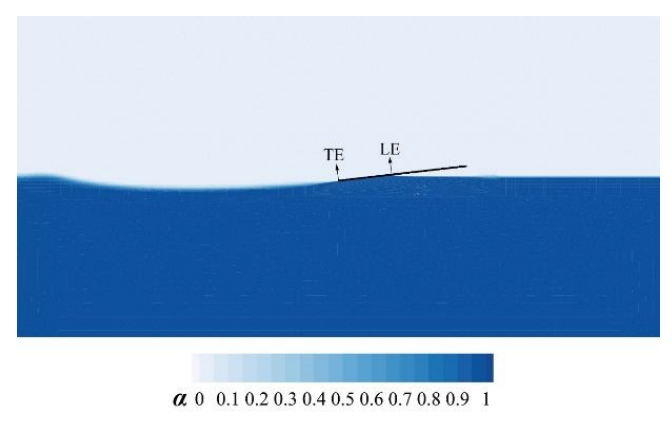

(a)

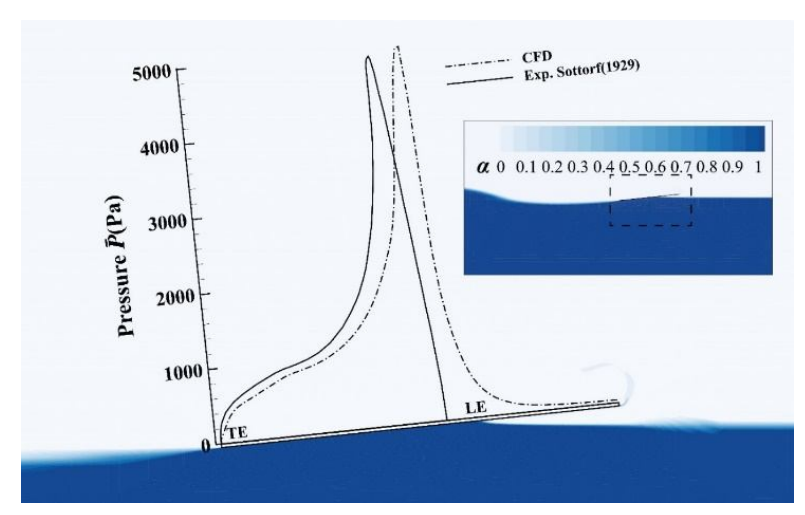

(b)

Fig. 4. a) Volume fraction $\alpha$ distribution ( 0 and 1 indicates the air and water, respectively) around the flat plate planing at advance velocity of $U=6 \mathrm{~m} / \mathrm{s}$, trim angle of $\theta=-6.53^{\circ}$, and the length below the undisturbed water free surface of $l=0.250 \mathrm{~m}$, and b) CFD predictions of pressure distribution around the flat plate planing at $U=6 \mathrm{~m} / \mathrm{s}, \theta=-6.0^{\circ}$, and $l=0.370 \mathrm{~m}$ in comparison with experiments carried out by Sottorf [91]

Comparison error for underpredicted resistance obtained by the numerical modeling was around $6 \%$ of the measured resistance. Error sources are attributed by numerical analysis, truncation error for instance, and/or uncertainties in experimental measurements. Nevertheless, it could be mainly due to the spray phenomenon, which is common in planing mode, that has not been elaborately modeled in the numerical analysis and neither has the portion of spray resistance in the total resistance. As shown in Fig. 4a the Leading Edge (LE) describes the front edge of the flat plate facing the incoming water flow where the stagnation point, and the maximum pressure are anticipated in its neighborhood. Moving towards the stern, the pressure is expected to dwindle along the plate length and reach atmospheric pressure at the transom or Trailing Edge (TE) where the water leaves the plate accompanied by a wake contributing substantially to the presence of a wave trough aft of the transom. CFD predictions of pressure distribution along the longitudinal center line of the flat plate are plotted in Fig. 4b in comparison with those measured by Sottorf [91]. Even though there exist some discrepancies, there is a close resemblance in general trend between numerical results and experimental data; pressure ascends abruptly at LE to a maximum of $4996 \mathrm{~Pa}$ and $4911 \mathrm{~Pa}$ for CFD and experiment, respectively. Afterwards, it gradually descends to a minimum pressure of around zero at TE. Although the exact position of maximum pressure is slightly different in two methods, the error in maximum pressure magnitude is only $1.73 \%$. Difference in the position of maximum 
pressure might have been sourced from discrepancy in the location of stagnation line affected by the spray root line and the spray thickness in the experiment which have not been elaborately resolved in CFD. It is noted that in the mentioned circumstances, CFD predictions and experiments agree reasonably well.

\section{Experimental procedure}

In order to elaborately assess the impact of interaction between demi-hulls and fluid flow in various separations and Froude numbers on the catamaran dynamic response, 6DOF self-propulsion experiments were carried out. The self-propulsion test in 6DOF offers several important advantages over 2DOF captive test including: 1- Most of load cells, mechanical or electronic, used in captive tests measure force based on converting a dynamic or kinematic characteristic into a value indicating the force, transducing strain into voltage in a strain gauge sensor, for instance. Obviously, the quality and type of the sensor influence its accuracy. When evaluating the separation effect in a catamaran, a sensor with high accuracy and precision, and of course an expensive one, is needed to detect the difference in force. However, performing 6DOF self-propulsion test makes it possible to measure dynamic or kinematic characteristics of the vehicle directly and accurately being devoid of load cell.

2- Properly aligning the towing force provided by the carriage through dynamometer with propeller shaft is a complicated process especially in the case there is a shaft inclination where the thrust force has two horizontal and vertical components. Any misalignment or change in the thrust direction and magnitude may cause considerable deviation and error in the results. In the self-propulsion test the vehicle is thrust by propeller through its shaft rather than being towed by a carriage.

3- Because the center of rotation is not a fixed point, towing the vehicle even in 2DOF mode, free to pitch and heave, will restrict the freedom of center of rotation. However, the center of rotation same as the metacenter in static equilibrium, varies depending on the position of the center of pressure particularly for large trim angles. Therefore, because the position of center of rotation is not limited in self-propulsion 6DOF experiment, the quality of dynamic response assessment will be improved.

6DOF experiments are carried out in a basin of $160 \mathrm{~m}$ length, $40 \mathrm{~m}$ breadth and $3 \mathrm{~m}$ depth (averaged) for 11 different propeller revolutions $n$ and 5 distinct separation distances $s$ (Table 3) counted 55 separate conditions in total each of which is repeated a couple of times. Tests are conducted in a straight-line motion of $100 \mathrm{~m}$ length.

Table 3. 6DOF test cases

\begin{tabular}{llllllllllll}
\hline Propeller revolution, $n$ & $\mathrm{n}_{1}$ & $\mathrm{n}_{2}$ & $\mathrm{n}_{3}$ & $\mathrm{n}_{4}$ & $\mathrm{n}_{5}$ & $\mathrm{n}_{6}$ & $\mathrm{n}_{7}$ & $\mathrm{n}_{8}$ & $\mathrm{n}_{9}$ & $\mathrm{n}_{10}$ & $\mathrm{n}_{11}$
\end{tabular}




\begin{tabular}{cccccccccccc}
\hline Value (rpm) & 772 & 1661 & 2156 & 2632 & 3088 & 3404 & 3666 & 4022 & 4204 & 4511 & 4787 \\
Separation distance, $s$ & $\mathrm{~s}_{1}$ & $\mathrm{~s}_{2}$ & $\mathrm{~s}_{3}$ & $\mathrm{~s}_{4}$ & $\mathrm{~s}_{5}$ & & $\mathrm{~s}_{1} / \mathrm{L}$ & $\mathrm{s}_{2} / \mathrm{L}$ & $\mathrm{s}_{3} / \mathrm{L}$ & $\mathrm{s}_{4} / \mathrm{L}$ & $\mathrm{s}_{5} / \mathrm{L}$ \\
Value (m) & 0.13 & 0.24 & 0.32 & 0.41 & 0.73 & {$[-]$} & 0.11 & 0.20 & 0.27 & 0.34 & 0.61 \\
\hline
\end{tabular}

In so doing a wide range of Froude numbers will be obtained by different propeller revolutions and corresponding advanced velocities covering displacement, semi-planing and planing regimes. The revolutions were measured using a tachometer with accuracy of $\pm 1 \mathrm{rpm}$. The proposed propeller revolutions provide advance velocities within a range of approximately $0.6 \mathrm{~m} / \mathrm{s}<U<6 \mathrm{~m} / \mathrm{s}$ and corresponding Froude numbers of $0.175<\mathrm{Fr}$ $<1.75$ or speed coefficients of $0.482<C_{U}<4.82$. As well as separation to length ratios are within $0.11<s / L<$ 0.61 or separation to two times the demi-hull beam ratios of $0.41<s /(2 b)<2.31$.

The reasons behind this selection for the range of separation ratios were covering that of previous research into interference effects as well as some considerations in experiments. For instance, Zaghi, Broglia and Di Mascio [25] chose separation ratios between the two extremes of 0.167 and 0.3 whereas in some other cases separation ratios $s / L$ of $0.226-0.470$ [26], 0.15-0.81 [18], 0.2-0.5 [38], 0.2-1.0 [19,31], 0.12-0.39 [21], 0.2-0.4 [23], 0.17-0.23 [32], 0.2-0.8 [62], 0.2-0.5 [63], 0.2-0.4 [34], 0.226-0.4696 [28], 0.2-0.6 [29], and 0.09-0.5 [36] were investigated. Hence the two ends of the spectrum were the minimum of 0.09 and the maximum of 1.0. Intriguingly, the case of $s / L=0$ was also reported by some researchers examined the interference effects at high Froude numbers including Savitsky and Dingee [41], Sherman [45] (who studied $0<s / L<0.33$ ), Liu and Wang [42], Lee [44], and [57]. However, in the present study, the minimum amount of separation $s_{\min }$ was experimentally limited to approximately two times the propeller diameter $d_{p}\left(s_{\min }=2 \times d_{p} \approx 0.13 m \rightarrow s_{\min } / L=0.11\right)$ so that the interference effect does not significantly influence the propeller efficiency by disturbing the propeller inflow properties - the case of $s_{\min } / L=0$ was selected for numerical analysis instead. The increment (step) for the $s / L$ is roughly about 0.07 except for the opposite extreme, the maximum of $s_{\max } / L=0.61$, where it was chosen as the case of two isolated demi-hulls. Because according to the literature no interference effect is anticipated for that.

In view of the fact that the propeller revolution is kept constant for different separation distances, the delivered power $P_{D}$ to the propeller is assumed to be constant in all separation cases having the same revolution. Thus according to $P_{D}=(X . U) / \eta_{D}$ and under the assumption of having delivered efficiency $\eta_{D}$ unchanged for the same revolution in different separation distances, it can be concluded that an increase in advance speed $U$ equals a decrease in resistance $X$ and vice versa. Although the advance velocity is extracted by means of the Global Positioning System (GPS) sensor installed in the vehicle, it also is measured using a stationary digital camera 
capturing the position of the vehicle every $1 / 24$ second (24 frames per second) resulting in a higher accuracy. As well as the vehicle is equipped with an Inertial Measurement Unit (IMU) electronic sensor pack consisting of accelerometer, gyroscope and digital compass by which measuring trim angle was provided with an accuracy of $\pm 0.1^{\circ}$. Furthermore, as shown in Fig. 1 the sides of the demi-hulls were distinguished by black-and-white checkerboard patterns constituted of square grids $3.5 \mathrm{~cm}$ long in order to better clear the vehicle running attitude. Fig. 5 exemplifies test cases for different separation distances executed in the constant propeller revolution $\mathrm{n}_{5}$. It should be noted that advance velocity and Froude number are not necessarily constant and in fact in this occasion Fr increases as $s$ increases (see the spray and rooster tail phenomena for last case $\mathrm{s}_{5} / \mathrm{L}$ in Fig. 5e due to higher Fr).

(a)

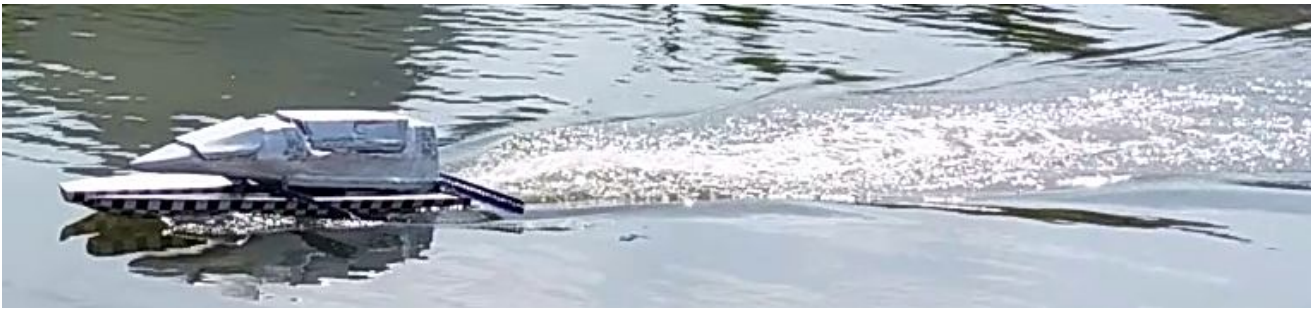

(b)

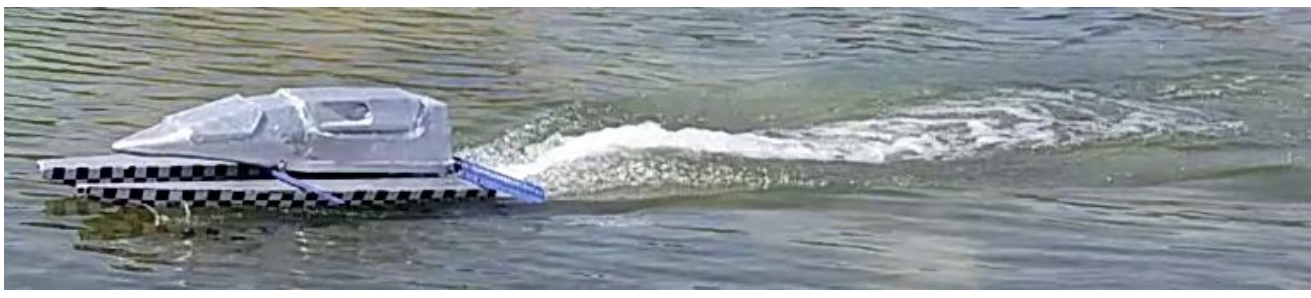

(c)

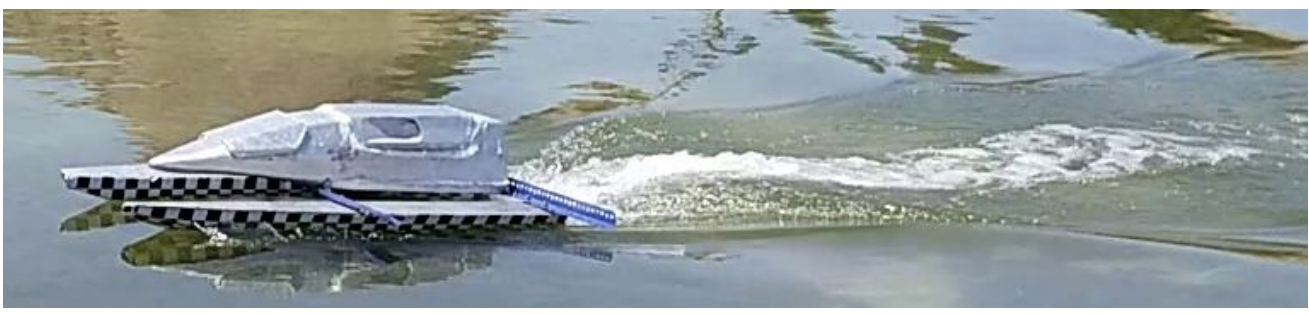

(d)

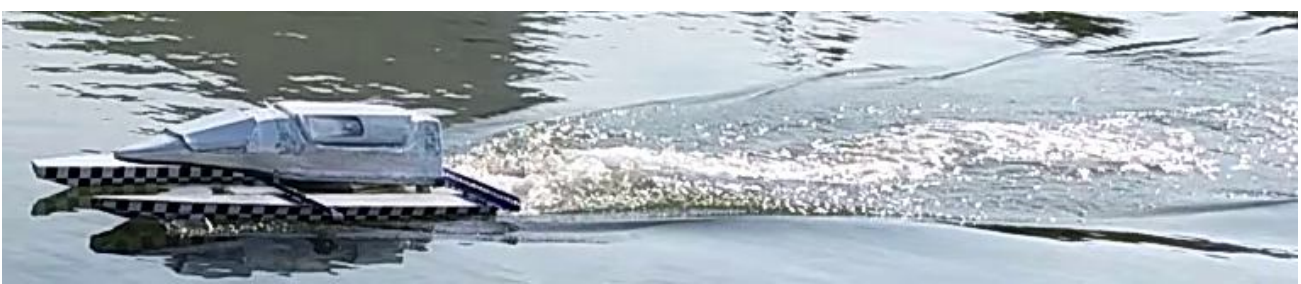

(e)

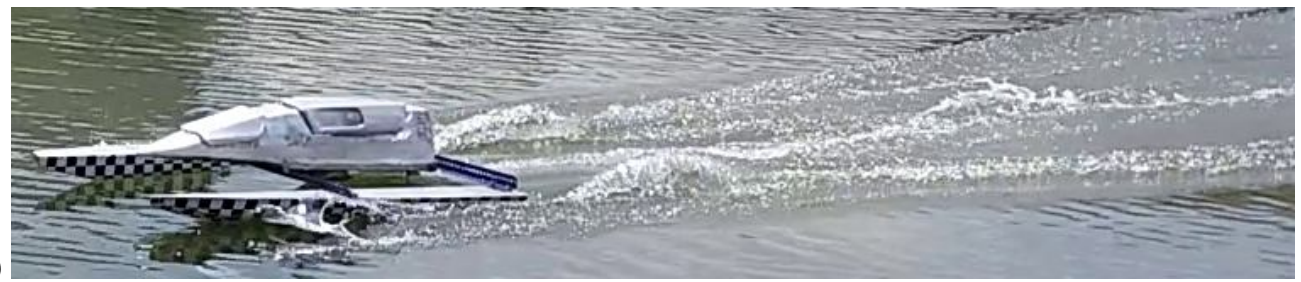


Fig. 5. $6 \mathrm{DOF}$ tests for the constant propeller revolution of $\mathrm{n}_{5}=3088 \mathrm{rpm}$ at different separation ratios $s / \mathrm{L}$, a) $\left.\left.\left.\left.\mathrm{s}_{1} / \mathrm{L}=0.11(\mathrm{Fr}=0.38), \mathrm{b}\right) \mathrm{s}_{2} / \mathrm{L}=0.2(\mathrm{Fr}=0.41), \mathrm{c}\right) \mathrm{s}_{3} / \mathrm{L}=0.27(\mathrm{Fr}=0.43), \mathrm{d}\right) \mathrm{s}_{4} / \mathrm{L}=0.34(\mathrm{Fr}=0.44), \mathrm{e}\right) \mathrm{s}_{5} / \mathrm{L}=0.61$ $(\mathrm{Fr}=0.45)($ please note the spray of water and rooster tail phenomena at the last case (e) indicating the highest Froude number and advance velocity and the lowest drag)

\section{Results and discussion}

\subsection{Experimental results}

Fig. 6 charts trim angle changes measured in 6DOF experiments for three propeller revolutions $\mathrm{n}_{1}, \mathrm{n}_{4}$, and $\mathrm{n}_{9}$ in a constant separation distance case $\mathrm{s}_{5}$ (the widest one). As shown in Fig. 6 trim initially stood at around $-3.7^{\circ}$ indicating the static trim when the boat was floating at rest. Afterwards, as motor was started, the propeller revolution $n$ rose from zero to the desired value of either $\mathrm{n}_{1}$, or $\mathrm{n}_{4}$, or $\mathrm{n}_{9}$. During this accelerating mode, hydrodynamic added mass forces and moments were acting on the vehicle and the trim tremendously leapt to maximum values of $-5.6^{\circ},-7.6^{\circ}$, and $-19^{\circ}$ for $\mathrm{n}_{1}, \mathrm{n}_{4}$, and $\mathrm{n}_{9}$, respectively. As $n$ increased, trim angle enlarged in magnitude demonstrating the fact that the center of pressure has moved forward since the pressure distribution no longer results merely from the hydrostatic pressure and it is also due to the dynamic pressure. Passing through the transient mode, trim began to gradually fall in magnitude until reaching a steady amount accompanying with some oscillations though. For instance, in this case, for the widest separation $s_{5}$, trim led to averaged values of $-4.13^{\circ}$, $-5.32^{\circ}$, and $-5.99^{\circ}$ for $\mathrm{n}_{1}, \mathrm{n}_{4}$, and $\mathrm{n}_{9}$, respectively.

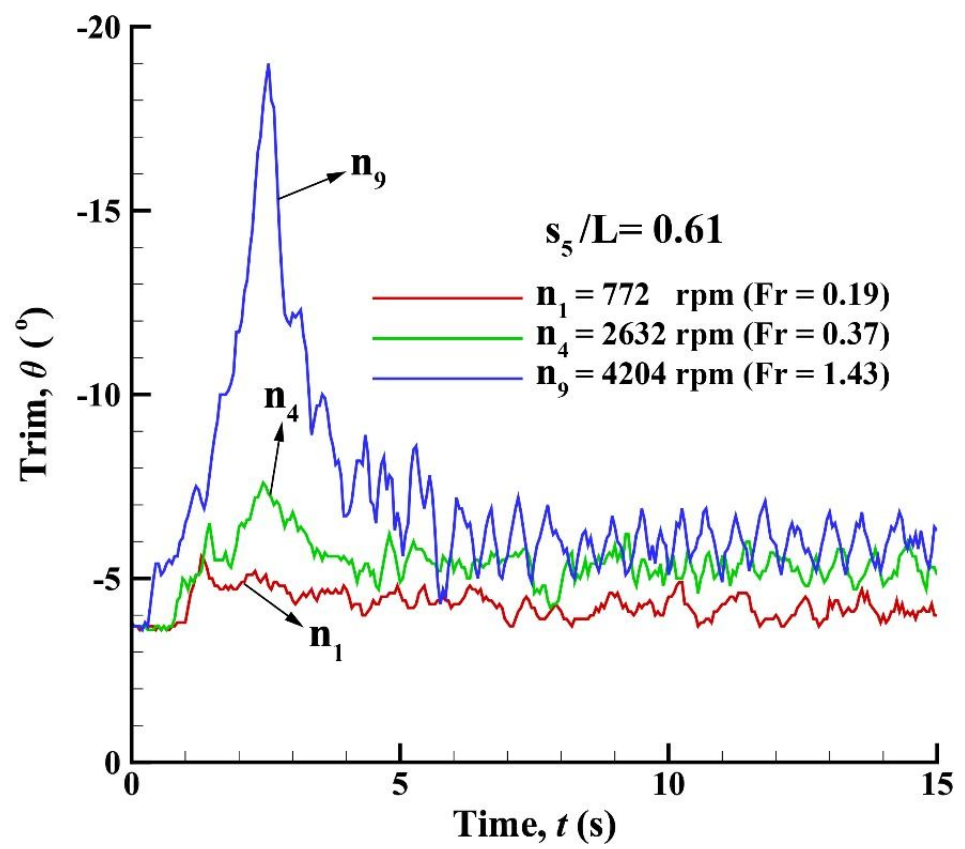


Fig. 6. Experimental data of trim angle changes in the widest separation $s_{5}$ in the straight-line motion of the catamaran for different propeller revolutions of $n_{1}(\mathrm{Fr}=0.19), \mathrm{n}_{4}(\mathrm{Fr}=0.37)$, and $\mathrm{n}_{9}(\mathrm{Fr}=1.43)$

Data recorded for the widest $s_{5}$ and narrowest $s_{1}$ separations in $n_{4}$ and $n_{11}$ are plotted on Fig. 7. The $n_{4}$ is of medium propeller revolution so that the vehicle is supposed to move in a moderate speed or alternatively stated displacement regime since the weight is mainly supported by the hydrostatic pressure. In comparison with the widest separation $s_{5}$, data in the narrowest separation $s_{1}$ reached a fewer amount of maximum trim in transient mode by discrepancy of $0.6^{\circ}$, whereas in the steady state mode it was trending upwards and finally reached the averaged value of $5.6^{\circ}$ slightly greater than that of the widest case $5.32^{\circ}$. It obviously demonstrates that the separation influences added mass forces and moments in addition to the steady drag force. In this case Fr is around 0.4-0.5 and according to Zaghi, Broglia and Di Mascio [25] the increase in trim is because of decreasing separation and the presence of a wave trough in the stern resulted from wave interference between demi-hulls. However, Zaghi, Broglia and Di Mascio [25] reported $1^{\circ}$ degree increase in trim angle while here it is around $0.3^{\circ}$. The difference might have been mainly due to the body form. ZRASV hull studied here is wall-sided inwards and Vshaped outwards so that significantly minimizes pressure or form drag and consequently wave interference between demi-hulls. Generally, in the displacement mode it can be highlighted that the presence of wave trough in stern region due to decreasing separation and wave interference, causes the center of pressure to move forward resulting in increasing trim angle.

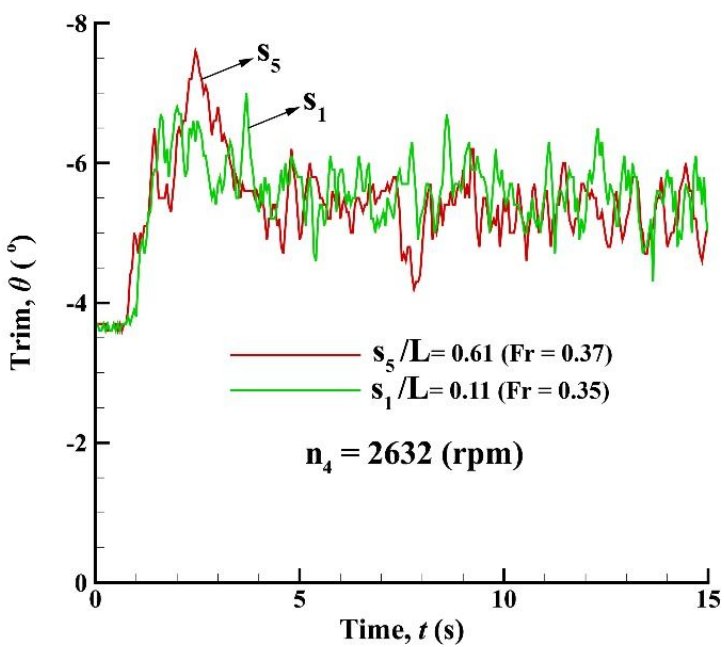

(a)

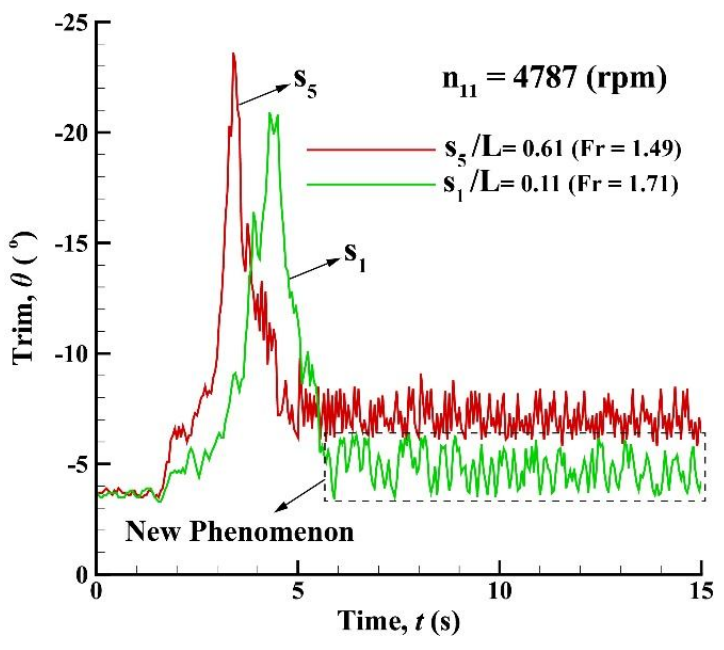

(b) 
Fig. 7. a) Experimental data of trim angle changes for the widest $s_{5}$ and the narrowest $s_{1}$ separations in the straight-line motion of the catamaran at the constant propeller revolutions of a) $n_{4}$ and b) $n_{11}$, the dashed rectangle depicts the reduction of trim magnitude at $\mathrm{s}_{1}$ because of the occurrence of the new phenomenon

Conflicting results, which are interesting, were obtained for Fr $>1.0$ also called semi-planing or planing regime. As displayed in Fig. $7 \mathrm{~b}$ where the vehicle is in the semi-planing or planing mode, in comparison with the displacement mode in Fig. 7a, it was found that the maximum trim angle in the transient region decreased by reduction in separation distance analogously. But the trim angle remarkably decreased at the steady state region for the narrowest separation $s_{1}$. As shown in Fig. $7 b$ trim angle initially saw the maximum values of $-23.6^{\circ}$ and $-20.9^{\circ}$, and then steadily arrived at averaged amounts of $-7.12^{\circ}$ and $-4.83^{\circ}$ for $s_{5}$ and $s_{1}$, respectively. Obviously, decreasing in trim angle by reduction in separation is in connection with having the center of pressure moved backward promising a new phenomenon.

Fig. 8 illustrates averaged trim angle and advance velocity changes against both the propeller revolution $n$ and the separation distance $s$ for all test cases. Apparently, it was revealed that trim angle manifested contrasting behavior before and after $\mathrm{n}_{6}=3404 \mathrm{rpm}$ where the Froude number is almost 0.75 indicating the boundary between displacement mode and semi-planing or planing mode. At the beginning, $n=0$, all cases stood at the static trim of around $-3.7^{\circ}$, next it slightly rose by increasing $n$ while remaining almost unchanged with respect to $s$ until $\mathrm{n}_{3}$ $=2156 \mathrm{rpm}$. Subsequently trim magnitude began to rise in a steeper slope by increasing $n$ and decreasing $s$ until reaching $\mathrm{n}_{6}=3404 \mathrm{rpm}$ and before that had seen the maximum discrepancy in separations for the narrowest $\mathrm{s}_{1}$ at $\mathrm{n}_{4}=2632 \mathrm{rpm}$ equivalent to $\mathrm{Fr}=0.4$ as great as $5 \%$ or $0.3^{\circ}$. Later on, in a surprising manner trim started to remarkably fall by increasing revolution $n$ and reducing separation $s$, representing the well-known behavior for planing region. However, for the widest separation $s_{5}$ it seems that entrance into planing region might have been lagged - see the unexpected growth in trim magnitude for the widest separation $\mathrm{s}_{5}$ in the maximum revolution $\mathrm{n}_{11}$ $=4787 \mathrm{rpm}$ in Fig. 8a. The maximum difference in separations was found at the maximum revolution $\mathrm{n}_{11}$ equivalent to $\mathrm{Fr}=1.6$ as great as $32 \%$ or $2.3^{\circ}$. 


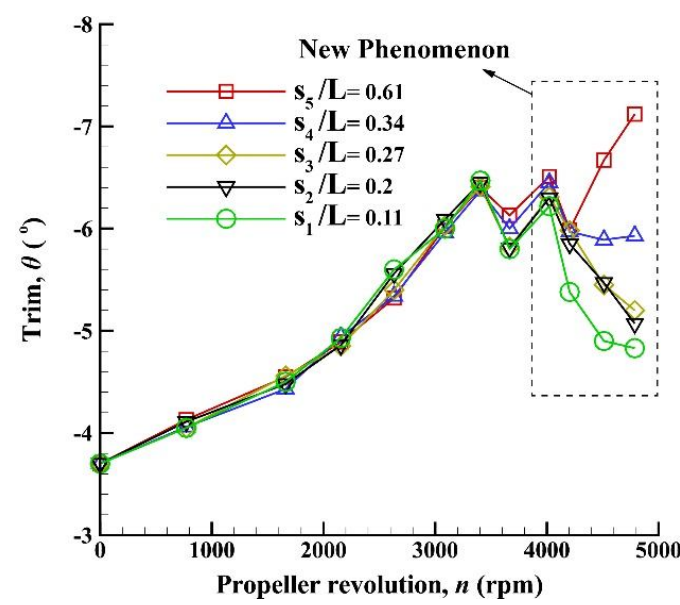

(a)

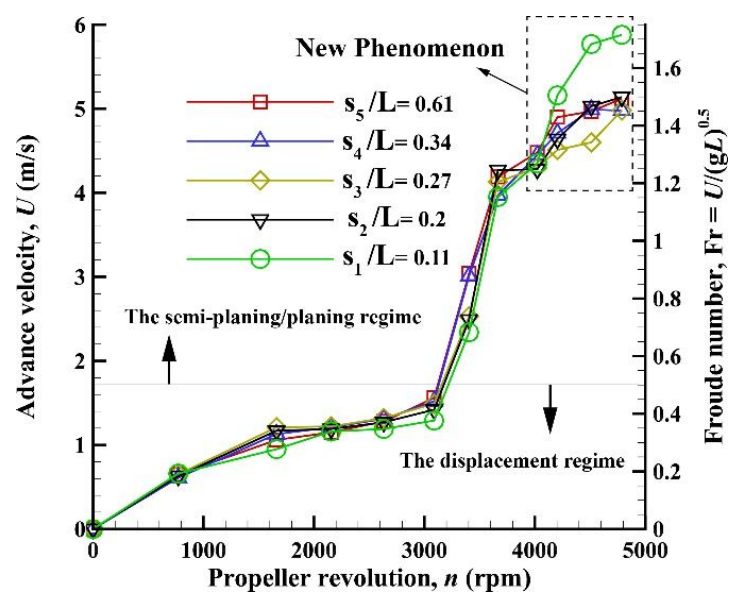

(b)

Fig. 8. a) Experimental data of trim angle changes (a) and advance velocity and Froude number (b) versus propeller revolution for various separations $\left(\mathrm{s}_{1}, \mathrm{~s}_{2}, \mathrm{~s}_{3}, \mathrm{~s}_{4}, \mathrm{~s}_{5}\right)$, dashed rectangles depict the reduction of trim (or the risk of porpoising instability) and increase of advance velocity (or reducing drag) by narrowing separation because of the occurrence of the new phenomenon at high propeller revolutions of $n_{8}=4022$ rpmand after it (the horizontal line at Fr $=0.5$ distinguishes the displacement regime from the semi-planing/planing regime)

As portrayed in Fig. 8b, it transpired that advance velocity trend substantially altered at $\mathrm{n}_{6}=3404 \mathrm{rpm}$ acting as a turning point in a manner like trim changes. Prior to this pivotal point, speed was raised moderately by rising propeller revolution up to $1.56 \mathrm{~m} / \mathrm{s}(\mathrm{Fr}=0.45)$ at $\mathrm{n}_{5}=3088 \mathrm{rpm}$ and slightly diminished by lowering separation distance signifying increase in resistance as a result of reduction in separation. Thereafter speed was abruptly boosted up to $3.04 \mathrm{~m} / \mathrm{s}$ at $\mathrm{n}_{6}$, nearly doubled in size with reference to $\mathrm{n}_{5}$, manifesting the transient state from displacement into semi-planing mode. Further comprising, advance velocity underwent maximum decline of $23 \%$ $(0.7 \mathrm{~m} / \mathrm{s})$ because of reduction in separation at $\mathrm{n}_{6}$, not to mention another decline of $10 \%$ at $\mathrm{n}_{2}=1661 \mathrm{rpm}$ following behind. These two sharp falls in velocity at $\mathrm{n}_{2}$ and $\mathrm{n}_{6}$ for the sake of narrowing separation distance bear a striking resemblance to the presence of two peaks in resistance-Froude number curve decisively associated with the existence of two wave troughs each one sequentially is located in the stern region between demi-hulls declared by $[22,24-27]$.

On the contrary, as soon as $\mathrm{n}_{6}$ was left behind, advance velocity astonishingly started to increase by decreasing the separation distance meaning that resistance or drag force was reduced which is highly advantageous. As an illustration in Fig. $8 \mathrm{~b}$ when rising propeller revolution from $\mathrm{n}_{5}=3088 \mathrm{rpm}$ to $\mathrm{n}_{11}=4787 \mathrm{rpm}, 55 \%$ increase in $n$, advance velocity tremendously climbed $355 \%$ from $1.29 \mathrm{~m} / \mathrm{s}$ to $5.88 \mathrm{~m} / \mathrm{s}$ for the narrowest separation $\mathrm{s}_{1}$. Indeed, 
the greatest discrepancy of $15 \%$ in velocity with respect to separation was observed at the maximum revolution $\mathrm{n}_{11}$ in which it arrived at $5.12 \mathrm{~m} / \mathrm{s}$ and $5.88 \mathrm{~m} / \mathrm{s}$ for the widest and the narrowest cases, respectively. Such a big drop in resistance might have been due to the reduction in viscous drag and so in wetted area.

As depicted in Fig. 8b, the horizontal borderline at $\mathrm{Fr}=0.5$ distinguishes the displacement regime from the semi-planing/planing regime - the Froude number at which the semi-planing mode commences as was introduced by Faltinsen [40] too. A discernible characteristic of semi-planing regime in resistance-velocity curve is the existence of a hump after which the resistance decreases by increasing velocity. A sharp increase of velocity by slightly rising the propeller revolution at $\mathrm{n}_{6}$, shown in Fig. $8 \mathrm{~b}$, is the sign of passing through that hump in resistance. As a result, the displacement mode comprises propeller revolutions of $\mathrm{n}_{1}, \mathrm{n}_{2}, \mathrm{n}_{3}, \mathrm{n}_{4}$, and $\mathrm{n}_{5}$ whereas the semi-planing/planing regime involves propeller revolutions of $\mathrm{n}_{6}, \mathrm{n}_{7}, \mathrm{n}_{8}, \mathrm{n}_{9}, \mathrm{n}_{10}$ and $\mathrm{n}_{11}$. It is not quite straightforward to discriminate between semi-planing and planing regimes, however, Fr > 1.2 may signify the planing regime [40] that includes propeller revolutions of $\mathrm{n}_{8}, \mathrm{n}_{9}, \mathrm{n}_{10}$ and $\mathrm{n}_{11}$.

In order to elucidate what happened in catamaran dynamic response for $\mathrm{n}_{5}$ and $\mathrm{n}_{11}$ test cases when the separation narrowed, Fig. 9 and Fig. 10 exhibit the vehicle moving forward at $n_{5}$ and $n_{11}$ under close observation for the widest $s_{5}$ and the narrowest $s_{1}$ separations, respectively. It is worth remembering that Fig. 9a and Fig. 9b had been shown in Fig. 5e and Fig. 5a from perspective view, respectively, where the spray and rooster tail phenomena occurred for the widest separation $\mathrm{s}_{5}$. Hence the presence of the latter should not be mistaken for wave crest in Fig. 9a, conversely both wave height and divergence angle for $\mathrm{s}_{5}$ are fewer than that of $\mathrm{s}_{1}$.

(a)

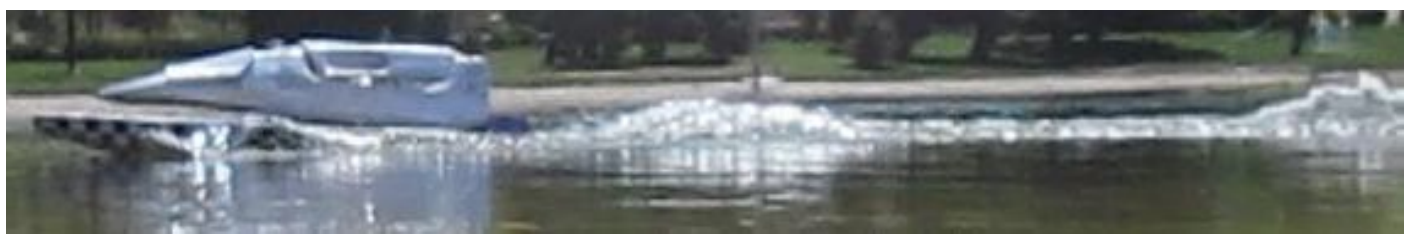

(b)

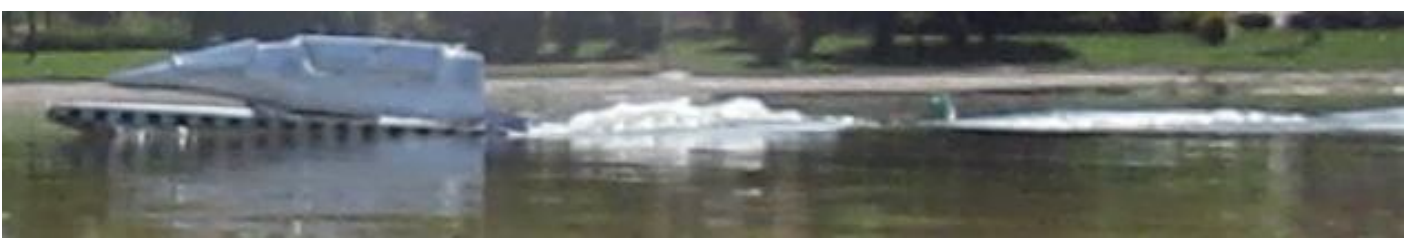

$$
\begin{array}{r}
s_{5} / L=0.61 \\
s_{1} / L=0.11
\end{array}
$$

(c)

\section{Undisturbed water} free surface

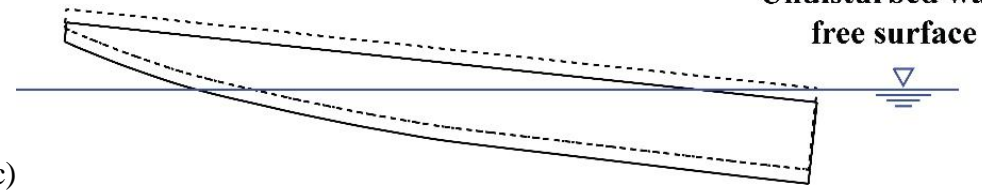


Fig. 9. $6 \mathrm{DOF}$ tests for the constant propeller revolution of $\mathrm{n}_{5}=3088 \mathrm{rpm}$ in the displacement mode for, a) the widest separation of $\mathrm{s}_{5} / \mathrm{L}=0.61, U=1.56 \mathrm{~m} / \mathrm{s}, \theta=-6.0^{\circ}$, and b) the narrowest separation of $\mathrm{s}_{1} / \mathrm{L}=0.11, U=$ $1.29 \mathrm{~m} / \mathrm{s}, \theta=-6.04^{\circ}$, and a sinkage of $12 \mathrm{~mm}$ compared to (a), and c) running attitude of the vehicle at the widest $s_{5}$ and the narrowest $s_{1}$ separations compared to the position of undisturbed water free surface (note: please do not mistake the water spray and rooster tail phenomena behind the vehicle at (a) for the wave as it was also shown in Fig. 5e from another view)

In fact, as depicted in Fig. 9 as separation distance shortened from $s_{5}$ to $s_{1}$ in $n_{5}$ case the vehicle sank into the water by sinkage of $12 \mathrm{~mm}$ with reference to the widest separation $\mathrm{s}_{5}$. Although the trim angle for $\mathrm{s}_{1}$ slightly increased by a narrow margin of less than $0.1^{\circ}$ compared to $\mathrm{s}_{5}$, the variation in trim angle was not as great as that of $\mathrm{n}_{4}$ case, $0.3^{\circ}$. What is more, shortening separation distance caused lowering the advance velocity from $1.56 \mathrm{~m} / \mathrm{s}$ $(\mathrm{Fr}=0.45)$ for $\mathrm{s}_{5}$ to $1.29 \mathrm{~m} / \mathrm{s}(\mathrm{Fr}=0.38)$ for $\mathrm{s}_{1}$, namely $17 \%$, at constant revolution of $\mathrm{n}_{5}$. This implies that decreasing separation distance resulted in increasing drag force, trim angle, and sinkage that the reason behind it might mainly be the wave interference inside the demi-hulls leading to intensifying the wave-making resistance. Additionally, more sinkage causes increasing in wetted surface as well as viscous resistance added to total drag.

On the other hand, as the vehicle moving forward at the maximum propeller revolution $\mathrm{n}_{11}$ for the widest $\mathrm{s}_{5}$ and the narrowest $s_{1}$ separations can be observed in Fig. 10, surprisingly reduction in the separation has had an opposite effect on catamaran dynamic response compared to $\mathrm{n}_{5}$ test cases. In this semi-planing or planing mode, narrowing separation resulted in elevating velocity by $15 \%$, rise by $10 \mathrm{~mm}$ and reducing trim angle by $32 \%$. In other words, a novel constructive phenomenon named Honaryar has occurred for the sake of decreasing separation in semi-planing or planing mode by which not only does the total drag decreased but also the lift force increased as well as it is having center of pressure move backward. Therefore it causes lessening the risk of porpoising instability since for diminishing the risk of porpoising in addition to reducing trim angle, the lift coefficient must be increased too [92]. By carefully observing Fig. 10 it is perceivable that huge amount of water spray existing for the widest separation, has been vanished for the narrowest one demonstrating the reduction in spray drag and consequently total drag. 
(a)

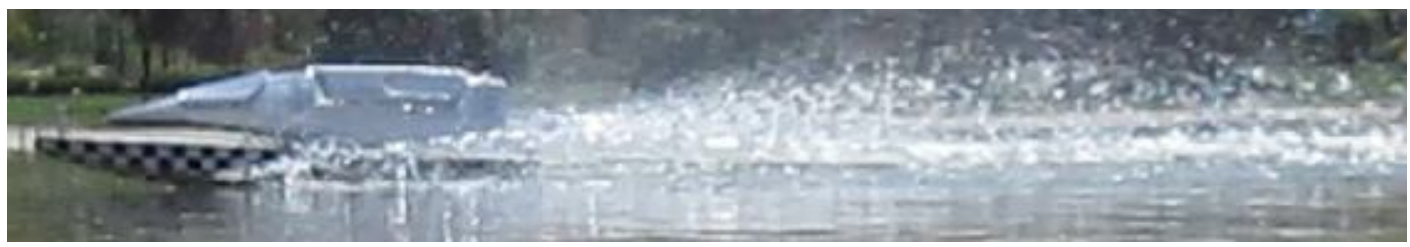

(b)

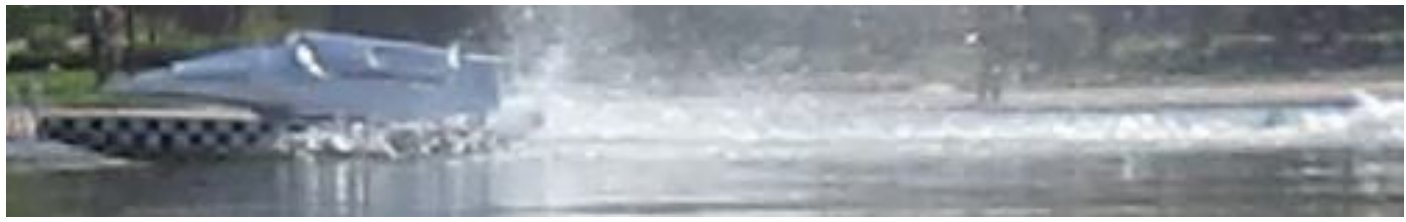

$\mathrm{s}_{5} / \mathbf{L}=\mathbf{0 . 6 1}$

$\mathbf{s}_{1} / \mathbf{L}=0.11$ (New Phenomenon)

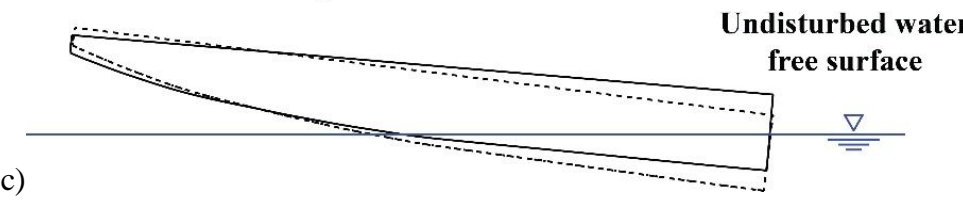

Fig. 10. $6 \mathrm{DOF}$ tests for the constant propeller revolution of $\mathrm{n}_{11}=4787 \mathrm{rpm}$ in the semi-planing/planing mode for, a) the widest separation of $\mathrm{s}_{5} / \mathrm{L}=0.61, U=5.12 \mathrm{~m} / \mathrm{s}, \theta=-7.12^{\circ}$, and b) the narrowest separation of $\mathrm{s}_{1} / \mathrm{L}=$ $0.11, U=5.88 \mathrm{~m} / \mathrm{s}, \theta=-4.83^{\circ}$, and a rise of $10 \mathrm{~mm}$ compared to (a), and c) running attitude of the vehicle at the widest $s_{5}$ and the narrowest $s_{1}$ separations compared to the position of undisturbed water free surface (please note the huge amount of water spray in (a) that has been vanished in (b) indicating an increase in velocity and reduction in drag at the narrowest separation for the sake of the new phenomenon (Honaryar phenomenon))

\subsection{CFD predictions}

Two cases $\mathrm{n}_{4}$ and $\mathrm{n}_{9}$ at the maximum separation $\mathrm{s}_{5}(s / L=0.61)$ were chosen representing items in the displacement mode and semi-planing mode, respectively. The vehicle running attitude and advance velocity measured in experiments at the maximum separation $\mathrm{s}_{5}, \mathrm{Fr}=0.37, U=1.28 \mathrm{~m} / \mathrm{s}, \theta=-5.32^{\circ}$, and $T_{a}=0.130 \mathrm{~m}$ for the case $\mathrm{n}_{4}$ and $\mathrm{Fr}=1.43, U=4.9 \mathrm{~m} / \mathrm{s}, \theta=-5.99^{\circ}$, and $T_{a}=0.105 \mathrm{~m}$ for the case $\mathrm{n}_{9}$, were input to the numerical analysis. The parameter $T_{a}$ signifies the aft draft of the vehicle indicating the height of undistributed free surface in the stern. Keeping the advance velocity, trim and heave of the vehicle constant, the separation ratio was reduced even to the amount of $s / L=0$ for both displacement and semi-planing cases.

Fig. 11 displays pressure distribution along one demi-hull against various separation ratios in the displacement mode. Pressure over the bottom and outer side is shown in Fig. 11a from bottom view and over the inner side plate is shown in Fig. 11b from side view. The pattern of pressure distribution is dominated by the hydrostatic pressure such that the pressure almost linearly increases in proportion to draft and is exerted by the water due to 
the gravity force. This pattern is customary in the displacement mode and, for instance, the pressure went up to more than $1000 \mathrm{~Pa}$ in the stern where its maximum value equals $\rho_{w} g T_{a} \simeq 1275 \mathrm{~Pa}$. At a glance in Fig. $11 \mathrm{a}$ it is discernible that because the pattern of pressure field remains unchanged, the separation effect on the pressure distribution over the bottom and outer side plates is negligible.
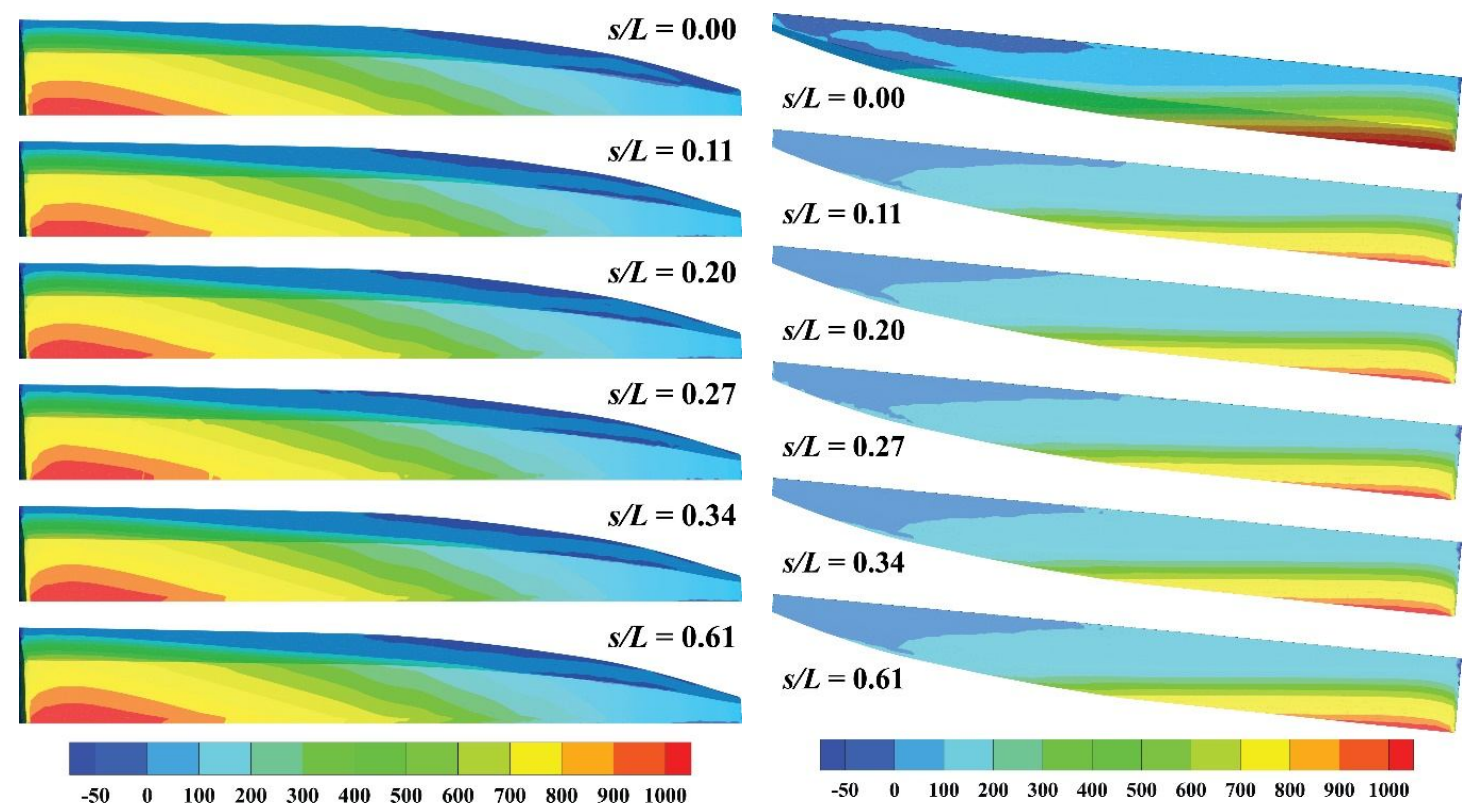

Pressure $(\mathrm{Pa})$

(a)

(b)

Pressure $(\mathrm{Pa})$

Fig. 11. Pressure distribution computed by CFD at displacement mode for the case of $\mathrm{Fr}=0.37, U=1.28 \mathrm{~m} / \mathrm{s}, \theta$

$=-5.32^{\circ}$, and $T_{a}=0.130 \mathrm{~m}$ imposing on a) bottom and outer side plates from bottom view, and $\mathrm{b}$ ) inner side

plate (wall-sided inwards except for the $s / L=0$ which shows the outer V-shaped side) from side view

In comparison with outer side, as shown in Fig. 11b, reduction in separation has altered pressure on the inner side. When comparing the maximum $s / L=0.61$ and the minimum $s / L=0.11$ separation ratios, it can be perceived that the maximum pressure has slightly decreased in the stern means the center of pressure has moved forwards that is why the vehicle was trimmed by aft as great as $0.3^{\circ}$ for the narrowest separation ratio more than that for the widest one in the experiments (see trim angles of the case $\mathrm{n}_{4}=2632 \mathrm{rpm}$ in Fig. 8 a for both $s / L=0.11$ and 0.61) and consequently the greater the trim magnitude is the greater drag force acts on the hull. The steady decline in pressure due to narrowing the separation also leads to producing less lift force explaining the more sinkage for the narrowest separation $s / L=0.11$ with reference to the widest one $s / L=0.61$ in experiments. Furthermore, as Fig. 11b illustrates, the pressure over the outer side $(s / L=0)$ is remarkably greater than that over the inner side 
(especially for the case $s / L=0.11$ ) indicating the difference in the wave pattern between inner and outer sides as well as existence of a cross flow which results in a more drag force (see the corresponding reduction in advance velocity due to increase in drag force for $s / L=0.11$ compared with $s / L=0.61$ at $\mathrm{n}_{4}=2632 \mathrm{rpm}$ in Fig. 8b).

The total pressure $P_{\text {total }}$ distribution presented in Fig. 11 is indeed the sum of the hydrostatic pressure $P_{\text {hyd }}$, the static pressure $P_{s}$ and the dynamic pressure $P_{d}$ as $P_{\text {total }}=P_{\text {hyd }}+P_{s}+P_{d}=\rho g T+P_{s}+1 / 2(\rho \overline{\boldsymbol{V}} \cdot \overline{\boldsymbol{V}})$ where T refers to draft or the height of water column. Hydrostatic pressure and dynamic pressure are coupled together, since the distribution of $\mathrm{T}$ is identified by the position of free surface of which profile is determined by computation of the volume fraction. According to Eq. (11), the volume fraction $\alpha$ is computed as soon as the velocity field $\overline{\boldsymbol{V}}$ makes known through solving RANS equations simultaneously. However, it is clearly evident that the hydrostatic pressure dominates the total pressure in the displacement mode. Because, for instance, it is expected that at the leading edge where the vehicle first encounters the water, there exists a stagnation point at which the local fluid velocity is zero and based on the Bernoulli's equation the stagnation pressure $P_{\text {stag }}$ consisting of dynamic pressure and static pressure $\left(P_{\text {stag }}=P_{d}+P_{s}\right)$ is maximum. There is, nevertheless, no sign of such a local rise in pressure at the leading edge (fore part) of the demi-hull in Fig. 11 demonstrating the hydrostatic pressure prevails over both dynamic and static pressures in the displacement mode i.e. $P_{h y d} \gg P_{d}+P_{s}$.

By carefully observing the flow physics in Fig. $11 \mathrm{~b}$ it is obvious that even in the case of widest separation ratio $s / L=0.61$, the pressure in the inner side is lower than that in the outer side for the sake of having asymmetric demi-hull. This noticeable pressure gradient causes a cross flow especially over the bottom edge also known as the keel. The resultant cross flow may result in the flow separation and subsequently increasing the drag force. Narrowing the demi-hull spacing further reduced the pressure in the inner side especially at the trailing edge (stern) that strengthens the cross flow and drag. The pressure reduction at the stern region in the inner side by shortening the demi-hulls separation ratio, might mainly be due to the interaction of transverse waves produced by each demi-hulls causing a wave trough near the stern as well as a decrease in the aft draft because of velocity field variations that resulted in locally reducing hydrostatic pressure and stagnation pressure.

On the contrary, findings from the semi-planing/planing mode appeared on the Fig. 12, where the Honaryar phenomenon is expected to occur, astoundingly revealed that not only does separation ratio affect pressure distribution over the inner side but it also influences pressure on the outer side and the bottom. Detailed observation on the pressure filed pattern in Fig. 12a demonstrates that pressure comprises a combination of hydrostatic and stagnation pressure $\left(P_{s}+P_{d}\right)$ in the semi-planing/planing mode. In the fore part of the demi-hull bottom in the proximity of leading-edge pressure distribution began to form a triangle whose hypotenuse 
represents the maximum pressure completely dominated by the stagnation pressure. According to Fig. 12a this triangular region of pressure seems not to be significantly a function of separation ratio except for the case $s / L=$ 0 in which the maximum pressure rose substantially - a similar behavior that exists in the wing theory for the sake of a rise in the effective aspect ratio.

In the aft part of the demi-hull bottom (Fig. 12a), however, pressure forms an elliptical shape whose center represents the maximum pressure. It seems that the stagnation pressure is not solely responsible for pressure pattern in this region and the hydrostatic pressure might have been still included - there is a slightly linear distribution of pressure with reference to draft in this region. Although the elliptical region of pressure in the aft part experienced an insignificant rise with respect to separation until $s / L=0.27$, pressure dramatically rose when further reducing the separation ratio to $s / L=0.2$ and 0.11 indicating a non-linear dependency on the separation ratio. An increase of pressure in the aft part of the inner side due to narrowing demi-hulls separation is also very conspicuous in Fig. 12b where additionally there is a decline in the low-pressure area happened in the aft part (in the stern) on the inner side. In summary, reducing separation ratio in the semi-planing/planing mode causes an increase in pressure in the aft part that leads to moving center of pressure backwards in addition to intensifying the lift force. Having center of pressure moved backwards explains the decline of $0.61^{\circ}$ in trim magnitude for the $s / L=0.11$ compared with $s / L=0.61$ in the Fig. 8 a for the case $\mathrm{n}_{9}=4204 \mathrm{rpm}$. The reason behind increasing lift force and having center of pressure moved backwards in the semi-planing/planing region after reducing separation ratio might have been due to the both inducing an upwash velocity and the lateral wave-interference effects of divergent waves at Fr > 1.0 investigated by Savitsky and Dingee [41] and Ma, Zhu, Wu, He, Zhang, Li and Noblesse [63], respectively. 

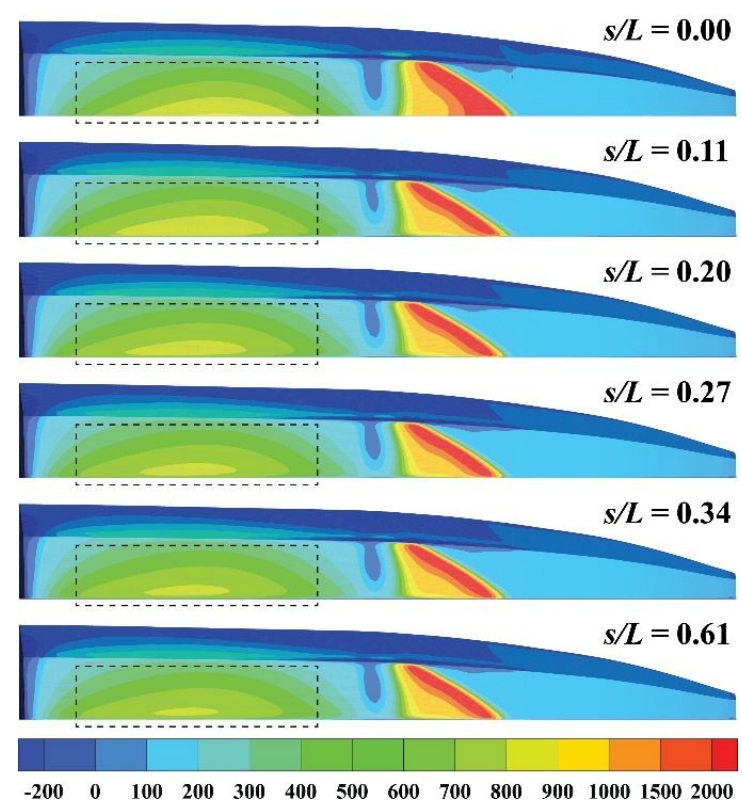

Pressure $(\mathrm{Pa})$

(a)

Fig. 12. Pressure distribution computed by CFD at semi-planing mode for the case of $\mathrm{Fr}=1.43, U=4.9 \mathrm{~m} / \mathrm{s}, \theta$

$=-5.99^{\circ}$, and $T_{a}=0.105 \mathrm{~m}$ imposing on a) bottom and outer side plates from bottom view, and b) inner side plate (wall-sided inwards except for the $s / L=0$ which shows the outer V-shaped side) from side view (please note the significant increase of pressure inside dashed rectangles by narrowing separation indicating the new

phenomenon occurrence at semi-planing mode)

In fact, the hypotenuse of triangular pressure pattern region in the leading edge illustrated in Fig. 12a indicates the maximum stagnation pressure of more than $2000 \mathrm{~Pa}$ that is also known as stagnation line. The stagnation line is also where in its neighborhood the water spray phenomenon is rooted. The spray root line can be seen in Fig. 10 for the case of $n_{11}$ that has occurred in the leading edge next to the stagnation line. However, the pressure at the leading edge in the opposite side, the inner side as displayed in Fig. 12b, is negative, i.e. neither hydrostatic pressure nor stagnation pressure acts on the vehicle. Therefore it can be perceived that there is no physical contact between water and hull in this negative pressure region. Another noticeable negative pressure region in the inner side has happened in the stern (or trailing edge, Fig. 12b) that means not only do not water and hull tough each other but also the transom will remain dry - the dry transom is convenient in planing crafts. It is interesting that reduction in the separation ratio weakened these two negative pressure areas, especially in the stern where the pressure has increased by narrowing separation ratio. Increasing the pressure in the inner side by means of reducing separation ratio lessens the cross flow in contrast to the displacement region. 
The results of pressure distribution in the two distinct displacement and semi-planing/planing modes reflected in computed lift and drag forces depicted in Fig. 13 too. Even though an approximately analogous trends were obtained for the drag force in the both modes, quite different and opposing trends were obtained for the lift force. By narrowing the separation distance from the widest ratio $(s / L=0.61)$ to zero, the drag magnitude grew steadily from $-8.48 \mathrm{~N}$ and $-34.02 \mathrm{~N}$ at $s / L=0.61$ to the maximum of $-9.04 \mathrm{~N}$ and $-35.24 \mathrm{~N}$ at $s / L=0.11$ and afterwards started to decline up to the minimum of $-7.06 \mathrm{~N}$ and $-33.02 \mathrm{~N}$ at $s / L=0$ for the displacement and the semiplaning/planing modes, respectively. Obviously, the minimum values of drag were obtained for $s / L=0$ where there is no space and consequently no wave as well as no wetted surface between demi-hulls resulting in decreasing wave-making and viscous resistance components.

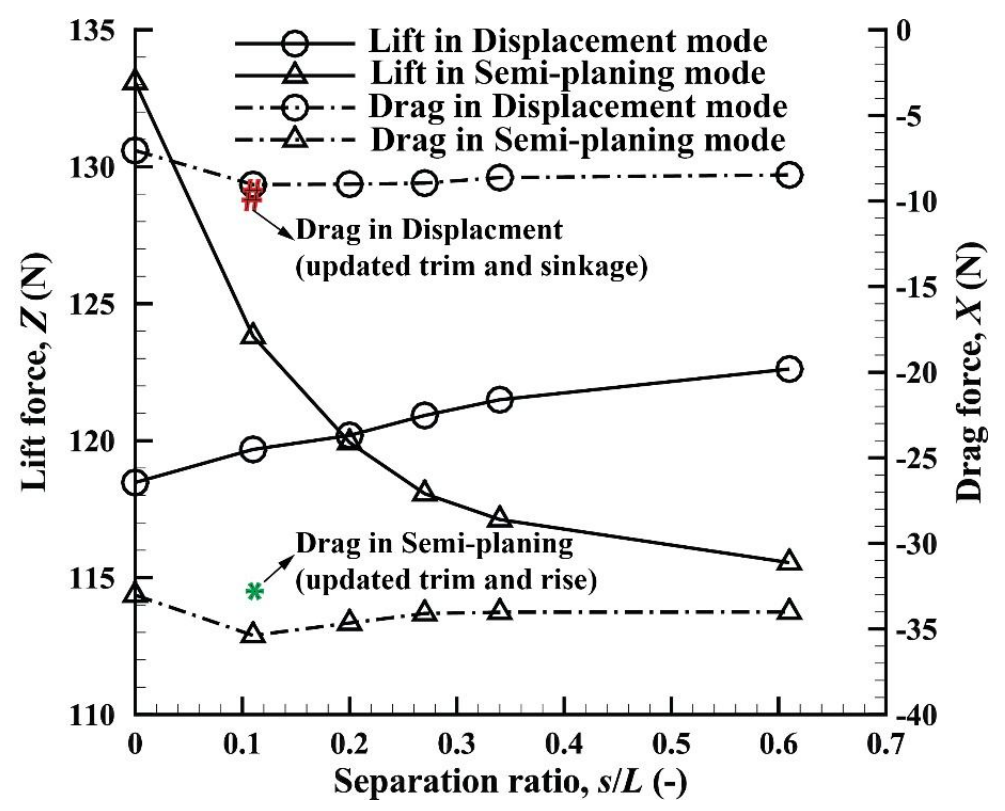

Fig. 13. Lift $Z$ and drag force $X$ variations against separation ratio $s / L$ at displacement mode (for the case of $U=$ $1.28 \mathrm{~m} / \mathrm{s}, \theta=-5.32^{\circ}$, and $T_{a}=0.130 \mathrm{~m}$ ) and semi-planing mode (for the case of $U=4.9 \mathrm{~m} / \mathrm{s}, \theta=-5.99^{\circ}$, and $T_{a}=0.105 \mathrm{~m}$ ) (please note that the maximum drag in displacement mode has been computed at the narrowest separation $\mathrm{s}_{1} / \mathrm{L}=0.1$ when updating trim and sinkage of the vehicle denoted by the hashtag (\#) whereas the minimum drag in semi-planing mode has been computed at the narrowest separation $\mathrm{s}_{1} / \mathrm{L}=0.1$ when updating trim and rise of the vehicle denoted by the asterisk $(*)$ indicating the new phenomenon)

After considering the effect of variation in trim along with sinkage and rise on the $s / L=0.11$, when the updated running attitude of $\theta=-5.39^{\circ}$ and $T_{a}=0.100 \mathrm{~m}$ in the semi-planing mode and $\theta=-5.6^{\circ}$ and $T_{a}=0.135 \mathrm{~m}$ in the 
displacement mode were input to the CFD from experiments, interestingly the further decrease of $7 \%$ (denoted by the asterisk $(*))$ in drag was obtained for the semi-planing mode because of reduction in wetted surface due to increase in rise (heave) and decrease in trim magnitude, whereas an additional unfavorable increase of $2 \%$ (denoted by the hashtag (\#)) in drag was obtained for the displacement mode because of an increase in the magnitude of sinkage and trim leading to increasing both form (pressure) and viscous drag components.

According to Fig. 13 the lift force in the displacement mode was gradually diminishing as separation distance narrowed and saw a drop of $3.38 \%$ at $s / L=0$ with respect to the widest separation ratio $s / L=0.61$ resulting in more sinkage. On the contrary in the semi-planing/planing mode as the separation ratio narrowed the lift force steadily increased until reaching $s / L=0.2$ and then dramatically grew with a steep slope up to the maximum increase of $13.18 \%$ resulting in a more rise. Such an increase in lift force as well as decreasing in trim magnitude or having center of pressure moved backwards lessen the risk of porpoising instability too.

\section{Conclusions}

The aim of this study was to investigate the effect of water-hull interaction and demi-dual-hull separation on catamaran hydrodynamic characteristics. In so doing a high-speed catamaran vehicle with asymmetric nonprismatic demi-hull was chosen to undergo experimental and numerical analysis from demi-hull interference effect point of view. Experiments in 6DOF were conducted to examine dynamic response of the vehicle in a wide range of Froude numbers $0.175<\mathrm{Fr}<1.75$ and separation ratios $0.11<s / L<0.61$ in order to cover different motion modes of displacement and semi-planing/planing. Findings in the displacement mode were found similar to those of previous research where interference effect played as an unfavorable phenomenon leading to increasing drag force by decreasing the separation ratio. The maximum fall of $23 \%$ in the advance velocity, corresponding to the same increase in the drag force, was observed at the constant propeller revolution of $\mathrm{n}_{6}=3404 \mathrm{rpm}$ as well as the maximum growth of $5 \%$ in the trim magnitude was measured at $\mathrm{n}_{4}=2632 \mathrm{rpm}$ for the displacement mode due to the reduction in separation ratio.

The interference effect played as a new advantageous phenomenon in the semi-planing/planing mode that had not been investigated before. This is an exciting finding. The maximum increase of $15 \%$ in advance velocity, of $10 \mathrm{~mm}$ in the rise (heave), and the maximum decline of $32 \%$ in the trim magnitude were obtained interestingly resulting in reducing drag force and lessening the risk of porpoising instability, respectively. Furthermore, simulations employed by CFD as an appropriate complementary tool strongly supported experimental data and presented elaborate results demonstrating pressure distribution, lift, and drag forces dependency on the separation 
ratio in both displacement and semi-planing/planing modes. Although having center of pressure moved forwards, a fall in lift force and an increase in drag force due to reduction in separation ratio were predicted in the displacement mode, completely opposing favorable results were acquired in the semi-planing/planing mode where the new phenomenon of this study occurred. Finally, the separation distance can be suggested as an effective control parameter to adjust both the velocity and trim angle of a high-speed catamaran in constant power.

\section{Acknowledgements}

The authors would like to express their gratitude and appreciation towards their affiliations, Amirkabir University of Technology and Newcastle University. Dr. Mehdi Iranmanesh, associate professor in Department of Maritime Engineering at Amirkabir University of Technology, is also highly acknowledged for his supports and suggestions.

\section{References}

[1] Feng X, Bai W. Hydrodynamic analysis of marine multibody systems by a nonlinear coupled model. J Fluids Struct 2017;70:72-101. https://doi.org/10.1016/j.jfluidstructs.2017.01.016.

[2] Faltinsen OM, Rognebakke OF, Timokha AN. Two-dimensional resonant piston-like sloshing in a moonpool. vol. 575. 2007. https://doi.org/10.1017/S002211200600440X.

[3] Jiang S, Tang P, Zou L, Liu Z. Numerical simulation of fluid resonance in a moonpool by twin rectangular hulls with various configurations and heaving amplitudes. J Ocean Univ China 2017;16:422-36. https://doi.org/10.1007/s11802-017-3147-5.

[4] Porter R, Evans D V. Water-wave trapping by floating circular cylinders. J Fluid Mech 2009;633:31125. https://doi.org/10.1017/S0022112009006831.

[5] Wang CZ, Meng QC, Huang HC, Khoo BC. Finite element analysis of nonlinear wave resonance by multiple cylinders in vertical motions. Comput Fluids 2013;88:557-68. https://doi.org/10.1016/j.compfluid.2013.10.012.

[6] Ok HT, Lee SJ, Choi JH. Numerical simulation of motion of single and side-by-side vessels in regular waves using OpenFOAM. Ships Offshore Struct 2017;12:793-803. https://doi.org/10.1080/17445302.2016.1265697.

[7] Qin H, Mu L, Tang W, Hu Z. Numerical study of the interaction between peregrine breather based freak waves and twin-plate breakwater. J Fluids Struct 2019;87:206-27. https://doi.org/10.1016/j.jfluidstructs.2019.04.003.

[8] Abbasnia A, Ghiasi M. A fully nonlinear wave interaction with an array of submerged cylinders by NURBS numerical wave tank and acceleration potential. Ships Offshore Struct 2014;9:404-17. https://doi.org/10.1080/17445302.2013.819688.

[9] Sabbagh-Yazdi SR, Bavandpour M. Numerical experiments on using incline collar rings for controlling mean and fluctuating forces on circular bridge piers. J Fluids Struct 2019;91:102696. https://doi.org/10.1016/j.jfluidstructs.2019.102696.

[10] Liu P. Propulsive performance of a twin-rectangular-foil propulsor in a counterphase oscillation. J Sh Res 2005;49:207-15.

[11] Hosseinjani AA, Ashrafizadeh A. Flow Confinement Effects on the Wake Structure behind a Pitching 
Airfoil: A Numerical Study Using an Immersed Boundary Method. J Bionic Eng 2017;14:88-98. https://doi.org/10.1016/S1672-6529(16)60380-3.

[12] Olivieri S, Boragno C, Verzicco R, Mazzino A. Constructive interference in a network of elasticallybounded flapping plates. J Fluids Struct 2019;90:334-53. https://doi.org/10.1016/j.jfluidstructs.2019.07.009.

[13] Wang J, Liu P, Chin C, He G. Numerical investigation of auto-pitch wing-in-ground effect oscillating foil propulsor. Appl Ocean Res 2019;89:71-84. https://doi.org/10.1016/j.apor.2019.05.015.

[14] Wang J, Liu P, Chin C, He G, Song W. Parametric study on hydro-elasticity characteristics of auto-pitch wing-in-ground effect oscillating foil propulsors. Ocean Eng 2020;201:107115. https://doi.org/10.1016/j.oceaneng.2020.107115.

[15] Liu P. A computational hydrodynamics method for horizontal axis turbine - Panel method modeling migration from propulsion to turbine energy. Energy 2010;35:2843-51. https://doi.org/10.1016/j.energy.2010.03.013.

[16] Liu P. WIG (wing-in-ground) effect dual-foil turbine for high renewable energy performance. Energy 2015;83:366-78. https://doi.org/10.1016/j.energy.2015.02.034.

[17] Yun L, Bliault A, Zong H. High speed catamarans and multihulls. 2019. https://doi.org/https://doi.org/10.1007/978-1-4939-7891-5.

[18] Dancig AA, Bunt EA. Wave interference effects on a double-hull ship model, as measured by gravity dynamometer. Int J Mech Sci 1990;32:653-76. https://doi.org/10.1016/0020-7403(90)90008-7.

[19] Moraes HB, Vasconcellos JM, Latorre RG. Wave resistance for high-speed catamarans. Ocean Eng 2004;31:2253-82. https://doi.org/10.1016/j.oceaneng.2004.03.012.

[20] Yanuar, Ibadurrahman. An investigation of the pentamaran resistance characteristic with variance in hull combination and configuration. Energy Procedia 2019;156:469-74.

https://doi.org/10.1016/j.egypro.2018.11.080.

[21] Lee SH, Lee YG, Kim SH. On the development of a small catamaran boat. Ocean Eng 2007;34:206173. https://doi.org/10.1016/j.oceaneng.2007.02.011.

[22] Souto-Iglesias A, Zamora-Rodríguez R, Fernández-Gutiérrez D, Pérez-Rojas L. Analysis of the wave system of a catamaran for CFD validation. Exp Fluids 2007;42:321-32. https://doi.org/10.1007/s00348006-0244-4.

[23] Tarafder SM, Suzuki K. Computation of wave-making resistance of a catamaran in deep water using a potential-based panel method. Ocean Eng 2007;34:1892-900. https://doi.org/10.1016/j.oceaneng.2006.06.010.

[24] Zaghi S, Broglia R, Mascio A Di. Experimental and numerical investigations on fast catamarans interference effects. J Hydrodyn 2010;22:545-9. https://doi.org/10.1016/S1001-6058(09)60250-X.

[25] Zaghi S, Broglia R, Di Mascio A. Analysis of the interference effects for high-speed catamarans by model tests and numerical simulations. Ocean Eng 2011;38:2110-22. https://doi.org/10.1016/j.oceaneng.2011.09.037.

[26] Souto-Iglesias A, Fernández-Gutiérrez D, Pérez-Rojas L. Experimental assessment of interference resistance for a Series 60 catamaran in free and fixed trim-sinkage conditions. Ocean Eng 2012;53:3847. https://doi.org/10.1016/j.oceaneng.2012.06.008.

[27] Broglia R, Jacob B, Zaghi S, Stern F, Olivieri A. Experimental investigation of interference effects for high-speed catamarans. Ocean Eng 2014;76:75-85. https://doi.org/10.1016/j.oceaneng.2013.12.003.

[28] Farkas A, Degiuli N, Martić I. Numerical investigation into the interaction of resistance components for a series 60 catamaran. Ocean Eng 2017;146:151-69. https://doi.org/10.1016/j.oceaneng.2017.09.043.

[29] Naz N, Karim MM. Investigation of hydrodynamic characteristics of high speed multihull vessels including shallow water effect. Procedia Eng 2017;194:51-8. https://doi.org/10.1016/j.proeng.2017.08.116. 
[30] Terziev M, Tezdogan T, Oguz E, Gourlay T, Demirel YK, Incecik A. Numerical investigation of the behaviour and performance of ships advancing through restricted shallow waters. J Fluids Struct 2018;76:185-215. https://doi.org/10.1016/j.jfluidstructs.2017.10.003.

[31] Millward A. The effect of hull separation and restricted water depth on catamaran resistance. Trans $\mathrm{R}$ Inst Nav Archit 1992;134:341-9.

[32] Castiglione T, He W, Stern F, Bova S. URANS simulations of catamaran interference in shallow water. J Mar Sci Technol 2014;19:33-51. https://doi.org/10.1007/s00773-013-0230-5.

[33] Hu J, Zhang Y, Wang P, Qing F. Numerical and experimental study on resistance of asymmetric catamaran with different layouts. Brodogradnja 2020;71:91-110. https://doi.org/10.21278/brod71206.

[34] Fitriadhy A, Razali NS, Aqilahmansor N. Seakeeping performance of a rounded hull catamaran in waves using CFD approach. J Mech Eng Sci 2017;11:2601-14. https://doi.org/10.15282/jmes.11.2.2017.4.0238.

[35] Yu D, Wang L, Yeung RW. Experimental and numerical study of ship-to-ship interactions in overtaking manoeuvres. Proc R Soc A Math Phys Eng Sci 2019;475. https://doi.org/10.1098/rspa.2018.0748.

[36] Li Y, Gong J, Ma Q, Yan S. Effects of the terms associated with $\phi z z$ in free surface condition on the attitudes and resistance of different ships. Eng Anal Bound Elem 2018;95:266-85. https://doi.org/10.1016/j.enganabound.2018.08.006.

[37] Chen X, Zhu R chuan, Song Y lan, Fan J. An investigation on HOBEM in evaluating ship wave of high speed displacement ship. J Hydrodyn 2019;31:531-41. https://doi.org/10.1007/s42241-018-0092-8.

[38] Insel M, Molland AF. An investigation into the resistance components of high speed displacement catamarans. R Inst Nav Archit 1992;134:1-20.

[39] Sahoo PK, Salas M, Schwetz A. Practical evaluation of resistance of high-speed catamaran hull forms Part I. Ships Offshore Struct 2007;2:307-24. https://doi.org/10.1080/17445300701594237.

[40] Faltinsen OM. Hydrodynamics of High_Speed Marine Vehicles. 2005.

[41] Savitsky D, Dingee DA. Some Interference Effects Between Two Flat Surfaces Planing Parallel to Each Other at High Speed. J Aeronaut Sci 1954;21:419-20. https://doi.org/10.2514/8.3057.

[42] Liu CY, Wang CT. Interference effect of catamaran planing hulls. J Hydronautics 1979;13:31-2.

[43] Savitsky D. Hydrodynamic design of planing hulls. Mar Technol 1964;1:71-95.

[44] Lee T. Interference factor for catamaran planing hulls. AIAA 1982;20:1461-2.

[45] Sherman TJ, Fisher PA, Couch RB. A study of planing catamaran hull and tunnel interactions. Off Nav Res Nav Ships Syst Command 1975.

[46] Wu GX. Numerical simulation of water entry of twin wedges. J Fluids Struct 2006;22:99-108. https://doi.org/10.1016/j.jfluidstructs.2005.08.013.

[47] Faltinsen OM, Semenov YA. Nonlinear problem of flat-plate entry into an incompressible liquid. J Fluid Mech 2008;611:151-73. https://doi.org/10.1017/S0022112008002735.

[48] Jalalisendi M, Porfiri M. Water entry of compliant slender bodies: Theory and experiments. Int J Mech Sci 2018;149:514-29. https://doi.org/10.1016/j.ijmecsci.2017.07.041.

[49] Xie H, Liu F, Yu P, Ren H. Comparative study on fluid dynamic behavior and slamming loads of two bow-flare sections entering into water. Int J Mech Sci 2020;166:105177. https://doi.org/10.1016/j.ijmecsci.2019.105177.

[50] Mayer HC, Krechetnikov R. Flat plate impact on water. J Fluid Mech 2018;850:1066-116. https://doi.org/10.1017/jfm.2018.461.

[51] Wang A, Duncan JH. The controlled vertical impact of an inclined flat plate on a quiescent water surface. J Fluid Mech 2019:465-511. https://doi.org/10.1017/jfm.2019.630.

[52] Shademani R, Ghadimi P. Parametric investigation of the effects of deadrise angle and demi-hull 
separation on impact forces and spray characteristics of catamaran water entry. J Brazilian Soc Mech Sci Eng 2017;39:1989-99. https://doi.org/10.1007/s40430-016-0679-3.

[53] Yousefnezhad R, Zeraatgar H. A parametric study on water-entry of a twin wedge by boundary element method. J Mar Sci Technol 2014;19:314-26. https://doi.org/10.1007/s00773-013-0250-1.

[54] Shabani B, Lavroff J, Holloway DS, Davis MR, Thomas GA. The effect of centre bow and wet-deck geometry on wet-deck slamming loads and vertical bending moments of wave-piercing catamarans. Ocean Eng 2018;169:401-17. https://doi.org/10.1016/j.oceaneng.2018.09.028.

[55] McVicar J, Lavroff J, Davis MR, Thomas G. Fluid-structure interaction simulation of slam-induced bending in large high-speed wave-piercing catamarans. J Fluids Struct 2018;82:35-58.

[56] Shabani B, Lavroff J, Davis MR, Holloway DS, Thomas GA. Slam loads and pressures acting on highspeed wave-piercing catamarans in regular waves. Mar Struct 2019;66:136-53. https://doi.org/10.1016/j.marstruc.2019.03.007.

[57] Yengejeh MA, Amiri MM, Mehdigholi H, Seif MS, Yaakob O. Numerical study on interference effects and wetted area pattern of asymmetric planing catamarans. Proc Inst Mech Eng Part M J Eng Marit Environ 2016;230:417-33. https://doi.org/10.1177/1475090215586638.

[58] Mousaviraad SM, Wang Z, Stern F. URANS studies of hydrodynamic performance and slamming loads on high-speed planing hulls in calm water and waves for deep and shallow conditions. Appl Ocean Res 2015;51:222-40. https://doi.org/10.1016/j.apor.2015.04.007.

[59] Bari GS, Matveev KI. Hydrodynamics of single-deadrise hulls and their catamaran configurations. Int J Nav Archit Ocean Eng 2017;9:305-14. https://doi.org/10.1016/j.ijnaoe.2016.11.001.

[60] Bari GS, Matveev KI. Hydrodynamic modeling of planing catamarans with symmetric hulls. Ocean Eng 2016;115:60-6. https://doi.org/10.1016/j.oceaneng.2016.01.035.

[61] Kramer MR, Maki KJ, Young YL. Numerical prediction of the flow past a 2-D planing plate at low Froude number. Ocean Eng 2013;70:110-7. https://doi.org/10.1016/j.oceaneng.2013.06.004.

[62] He J, Zhang C, Zhu Y, Zou L, Li W, Noblesse F. Interference effects on the Kelvin wake of a catamaran represented via a hull-surface distribution of sources. Eur J Mech B/Fluids 2016;56:1-12. https://doi.org/10.1016/j.euromechflu.2015.10.009.

[63] Ma C, Zhu Y, Wu H, He J, Zhang C, Li W, et al. Wavelengths of the highest waves created by fast monohull ships or catamarans. Ocean Eng 2016;113:208-14. https://doi.org/10.1016/j.oceaneng.2015.12.042.

[64] Tafuni A, Sahin I, Hyman M. Numerical investigation of wave elevation and bottom pressure generated by a planing hull in finite-depth water. Appl Ocean Res 2016;58:281-91. https://doi.org/10.1016/j.apor.2016.04.002.

[65] Wan H, Yeung RW. Interaction of bodies in free surface with consideration of cross-flow. Comput Fluids 2012;54:127-42. https://doi.org/10.1016/j.compfluid.2011.10.005.

[66] Dadmarzi FH, Narasimhamurthy VD, Andersson HI, Pettersen B. Turbulent wake behind side-by-side flat plates: Computational study of interference effects. J Fluid Mech 2018;855:1040-73. https://doi.org/10.1017/jfm.2018.649.

[67] Broglia R, Zaghi S, Campana EF, Dogan T, Sadat-Hosseini H, Stern F, et al. Assessment of computational fluid dynamics capabilities for the prediction of three-dimensional separated flows: The Delft 372 catamaran in static drift conditions. J Fluids Eng Trans ASME 2019;141:091105. https://doi.org/10.1115/1.4042752.

[68] Miao A, Zhao M, Wan D. CFD-based multi-objective optimisation of S60 Catamaran considering Demihull shape and separation. Appl Ocean Res 2020;97:102071. https://doi.org/10.1016/j.apor.2020.102071.

[69] Li X, Li K, Zhang L, Zhang H. Singularity analysis of response bifurcation for a coupled pitch - roll ship model with quadratic and cubic nonlinearity. Nonlinear Dyn 2019. https://doi.org/10.1007/s11071018-4714-z. 
[70] Dash AK, Nagarajan V, Sha OP. Bifurcation analysis of a high-speed twin-propeller twin-rudder ship maneuvering model in roll-coupling motion. Nonlinear Dyn 2016;83:2035-53. https://doi.org/10.1007/s11071-015-2463-9.

[71] Yang J, Lin Z, Li P, Guo Z, Sun H, Yang D. Experimental investigations on the resistance performance of a high-speed partial air cushion supported catamaran. Int J Nav Archit Ocean Eng 2020;12:38-47. https://doi.org/10.1016/j.ijnaoe.2019.05.004.

[72] Honaryar A, Ghiasi M. Design of a Bio-inspired Hull Shape for an AUV from Hydrodynamic Stability Point of View through Experiment and Numerical Analysis. J Bionic Eng 2018;15:950-9. https://doi.org/10.1007/s42235-018-0083-z.

[73] Honaryar A, Mousavizadegan SH, Ghassemi H. Simulation of Turning Circle Maneuver of a Catamaran Planing Boat with a Combined Experimental and Numerical Method. 10th Symp. High Speed Mar. Veh., Naple, Italy: 2014, p. 1-10.

[74] Pandey J, Hasegawa K. Study on Turning Manoeuvre of Catamaran Surface Vessel with a Combined Experimental and Simulation Method. IFAC-PapersOnLine 2016;49:446-51. https://doi.org/10.1016/j.ifacol.2016.10.446.

[75] Yu D, Lecointre P, Yeung RW. Experimentally-based investigation of effects of wave interference on the wave resistance of asymmetric di-hulls. Appl Ocean Res 2017;65:142-53. https://doi.org/10.1016/j.apor.2017.03.018.

[76] Thornhill E, Veitch B, Bose N. Dynamic instability of a high-speed planing boat model. Mar Technol Sname News 2000;37:146-52.

[77] Rakesh NNV, Rao PL, Subramanian VA. High-Speed Simulation in Towing Tank for Dynamic Lifting Vessels Nimmagadda. Proc. Fourth Int. Conf. Ocean Eng. (ICOE2018), Springer, Springer Singapore; 2019, p. 65-79. https://doi.org/10.1007/978-981-13-3119-0.

[78] Honaryar A, Iranmanesh M, Liu P, Honaryar A. Numerical and experimental investigations of outside corner joints welding deformation of an aluminum autonomous catamaran vehicle by inherent strain/deformation FE analysis. Ocean Eng 2020;200:106976. https://doi.org/10.1016/j.oceaneng.2020.106976.

[79] Fossen TI. Handbook of marine craft hydrodynamics and motion control. 2011. https://doi.org/10.1002/9781119994138.

[80] Moukalled F, Mangani L, Darwish M. The finite volume method in computational fluid dynamics. 2016.

[81] Ansys Inc. ANSYS CFX-solver theory guide. 2009.

[82] Hajmohammadi MR, Nourazar SS, Campo A. Analytical solution for two-phase flow between two rotating cylinders filled with power law liquid and a micro layer of gas. J Mech Sci Technol 2014;28:1849-54. https://doi.org/10.1007/s12206-014-0332-y.

[83] Yeoh GH, Barber T. Assessment of interface capturing methods in Computational Fluid Dynamics (CFD) codes - A case study. J Comput Multiph Flows 2009;1:201-15. https://doi.org/10.1260/175748209789563946.

[84] Ubbink O, Issa RI. A method for capturing sharp fluid interfaces on arbitrary meshes. J Comput Phys 1999;153:26-50. https://doi.org/10.1006/jcph.1999.6276.

[85] Tezdogan T, Demirel YK, Kellett P, Khorasanchi M, Incecik A, Turan O. Full-scale unsteady RANS CFD simulations of ship behaviour and performance in head seas due to slow steaming. Ocean Eng 2015;97:186-206. https://doi.org/10.1016/j.oceaneng.2015.01.011.

[86] Tezdogan T, Incecik A, Turan O. A numerical investigation of the squat and resistance of ships advancing through a canal using CFD. J Mar Sci Technol 2016;21:86-101. https://doi.org/10.1007/s00773-015-0334-1.

[87] ITTC. Practical guidelines for ship CFD applications. Proc. 26th ITTC, 2011, p. 1-8.

[88] Demirel YK, Turan O, Incecik A. Predicting the effect of biofouling on ship resistance using CFD. Appl 
Ocean Res 2017;62:100-18. https://doi.org/10.1016/j.apor.2016.12.003.

[89] Elsherbiny K, Terziev M, Tezdogan T, Incecik A, Kotb M. Numerical and experimental study on hydrodynamic performance of ships advancing through different canals. Ocean Eng 2020;195:106696. https://doi.org/10.1016/j.oceaneng.2019.106696.

[90] Zhang JT, Maxwell J a., Gerber AG, Holloway a. GL, Watt GD. Simulation of the flow over axisymmetric submarine hulls in steady turning. Ocean Eng 2013;57:180-96.

https://doi.org/10.1016/j.oceaneng.2012.09.016.

[91] Sottorf W. Experiments with planing surfaces. Natl Advis Comm Aeronaut 1929.

[92] Mansoori M, Fernandes AC. The interceptor hydrodynamic analysis for controlling the porpoising instability in high speed crafts. Appl Ocean Res 2016;57:40-51.

https://doi.org/10.1016/j.apor.2016.02.006. 